\title{
Differentially expressed proteins in positive versus negative HNSCC lymph nodes
}

\author{
Alessandra Vidotto', Giovana M. Polachini', Marina de Paula-Silva², Sonia M. Oliani², Tiago Henrique', \\ Rossana V. M. López ${ }^{3}$, Patrícia M. Cury ${ }^{4}$, Fabio D. Nunes ${ }^{5}$, José F. Góis-Filhoo ${ }^{6}$, Marcos B. de Carvalho ${ }^{7}$, \\ Andréia M. Leopoldino ${ }^{8}$ and Eloiza H. Tajara ${ }^{1,9^{*}}$
}

\begin{abstract}
Background: Lymph node metastasis is one of the most important prognostic factors in head and neck squamous cell carcinomas (HNSCCS) and critical for delineating their treatment. However, clinical and histological criteria for the diagnosis of nodal status remain limited. In the present study, we aimed to characterize the proteomic profile of lymph node metastasis from HNSCC patients.

Methods: In the present study, we used one- and two-dimensional electrophoresis and mass spectrometry analysis to characterize the proteomic profile of lymph node metastasis from HNSCC.

Results: Comparison of metastatic and non-metastatic lymph nodes showed 52 differentially expressed proteins associated with neoplastic development and progression. The results reinforced the idea that tumors from different anatomical subsites have dissimilar behaviors, which may be influenced by micro-environmental factor including the lymphatic network. The expression pattern of heat shock proteins and glycolytic enzymes also suggested an effect of the lymph node environment in controlling tumor growth or in metabolic reprogramming of the metastatic cell. Our study, for the first time, provided direct evidence of annexin A1 overexpression in lymph node metastasis of head and neck cancer, adding information that may be useful for diagnosing aggressive disease.
\end{abstract}

Conclusions: In brief, this study contributed to our understanding of the metastatic phenotype of HNSCC and provided potential targets for diagnostic in this group of carcinomas.

Keywords: Head and neck carcinoma, Metastasis, Lymph node, Proteomics

\section{Background}

Metastases are the main cause of death in cancer patients [1]. The power of these malignant cells to kill their hosts resides in their ability to leave the primary tumor, disseminate and invade ectopic sites, as well as to exhibit self-renewal and uncontrollable growth, leading to painful and incurable secondary tumors. In recent years, many data have revealed the determining factors mediating this destructive cascade, which include an extensive and growing list of genetic and epigenetic alterations [2].

\footnotetext{
* Correspondence: tajara@famerp.br

1Departamento de Biologia Molecular, Faculdade de Medicina (FAMERP), Av. Brigadeiro Faria Lima, 5416, Vila São Pedro, São José do Rio Preto, SP CEP 15090-000, Brazil

${ }^{9}$ Departamento de Genética e Biologia Evolutiva, Instituto de Biociências, Universidade de São Paulo, R. do Matão, 321, São Paulo, SP CEP 05508-090, Brazil

Full list of author information is available at the end of the article
}

In the initial steps of metastatization, tumor cell mutations and signals released by the stromal cells may cooperate to reduce cell-cell adhesion and to promote migration of epithelial neoplastic cells [3]. These events are similar to those of an important reversible differentiation program named epithelial-mesenchymal transition (EMT), which occurs during embryogenesis and have also been implicated in tumor invasion and metastasis [4].

As the tumor grows, low oxygen tension stimulates a proangiogenic response [5]. Due to cytokines secreted by neoplastic and stromal cells, endothelial cells from pre-existing blood vessels synthesize proteases, allowing their migration through the stroma [6]. These migrating endothelial cells proliferate and generate new vessels, which can supply oxygen and nutrients to sustain cancer growth and are an important route for metastasis [7]. Lymphatic vessel formation, a common event in various

(c) The Author(s). 2018 Open Access This article is distributed under the terms of the Creative Commons Attribution 4.0 International License (http://creativecommons.org/licenses/by/4.0/), which permits unrestricted use, distribution, and 
inflammatory conditions, is also stimulated in some human cancers [8] and evolves to an important route of spread of tumors cells to regional lymph nodes [9].

The lymphatic network is more permissive for metastatic spread than the blood vascular system because (a) the basement membranes of the vessels are incomplete, (b) their capillaries exhibit a single endothelial cell layer not surrounded by pericytes and (c) have intercellular valve-like structures that facilitate the uptake of cells [10]. In addition to the permissive structure, the hydrostatic pressure of the lymphatic system is lower compared to blood circulation, reducing the mechanical challenge [11]. Otherwise, lymph is richer in immune response factors which, although insufficient to destroy tumor cells [12], may play an important role in selecting immune resistance phenotypes [13]. Examples of tumors that frequently metastasize to regional lymph nodes via lymphatic route instead of spreading to distant sites are the head and neck carcinomas (HNSCC) [14], a group of neoplasms nearly always associated with chronic inflammation.

Arrival at a secondary site does not ensure success for most metastatic cells. The processes of extravasation and seeding require specific tumor characteristics and receptive conditions. To increase the chances of a favorable outcome, it has been suggested that target sites are prepared in advance by long-distance interaction with the primary tumor $[15,16]$. The pattern of metastatic seeding and colonization is not random and, depending on the primary site, tumor cells spread to particular organ sites more frequently than to others [17].

The mechanisms involved in metastasis organotropism are not completely known but chemokines and their receptors, as well as circulation patterns and structural features of local capillaries should be important contributors for the process [18]. Several critical genes driving organ-specific metastases have been described in different tumors [19, 20]. However, a number of questions remain unanswered. For example, in head and neck carcinomas, regional lymph nodes are the preferential target sites and distant metastases are a late and infrequent finding [21]. Why HNSCCs have this behavior and why small cell carcinomas of the head and neck [22] and several tumors of salivary gland [23], located in the same anatomical site, typically have distant metastases? The answer probably lies in the characteristics of the metastatic cell as well as in its interaction with the microenvironment.

Considering (a) the atypical feature of HNSCC to remain a locoregional disease, (b) the limitations of relapse risk assessment and (c) clinical and histological criteria for the diagnosis of lymph node spread, still the most powerful prognostic factor for these cancers [24], it is urgently necessary to define appropriate biomarkers of the metastatic phenotype for this group of diseases. In the present study, we aimed to characterize the proteomic profile of lymph node metastasis from HNSCC using one- and two-dimensional electrophoresis and mass spectrometry analysis.

\section{Methods \\ Tissue samples}

Thirty-two samples of lymph nodes (12 non-metastatic or $\mathrm{NO}$ and 20 metastatic or $\mathrm{N}+$ ) were obtained from patients with surgically resected head and neck squamous cell carcinomas of three anatomical subsites classified according to the 10th edition of the International Classification of Diseases-10: $\mathrm{C} 02$ = other and unspecified parts of tongue; C04 = floor of mouth; C32=larynx. Ten of the lymph node samples were derived from patients with tongue, 13 from floor of the mouth and 9 from larynx carcinomas and their extracted proteins were analyzed by either one-dimensional gel (1-D) or two-dimensional (2-D) gel electrophoresis. An overlapping set of 22 samples was analyzed by Western blot. Immunohistochemical staining was also performed using formalin-fixed, paraffinembedded blocks (14 lymph nodes and 9 surgical margins) and tissue microarray slides (65 primary tumors) containing samples from C02, C03 (gum), C04, C32 and C06 (other and unspecified parts of mouth) neoplasms. Therefore, two anatomical sites were analyzed: oral cavity (C02, C03, C04, C06 subsites) and larynx (C032).

Surgical specimens were obtained before radio- or chemotherapy by the Head and Neck Genome Project (GENCAPO), a collaborative consortium of research groups from hospitals and universities in São Paulo State, Brazil, whose aim is to develop clinical, genetic and epidemiological analysis of head and neck squamous cell carcinomas.

Immediately after surgery, part of specimen was frozen in liquid nitrogen and stored at $-80{ }^{\circ} \mathrm{C}$, and part was fixed in formalin for immunohistochemistry or routine histopathological examination. Frozen sections of the lymph nodes were analyzed to confirm the presence $(\mathrm{N}+)$ or absence (N0) of tumor cells. The primary tumors were classified by the Tumor-Node-Metastases (TNM) system [25]. A full description of the clinicopathological data is provided in Additional file 1.

The study protocol was approved by each institutional review board and by the National Committee on Ethics in Research/CONEP (reference number 1763/05, 18/05/ 2005). All patients provided written informed consent.

\section{Proteomic approaches Sample preparation}

Sample preparation was performed according to the protocol described by de Marqui et al. [26], with modifications. In brief, lymph node samples were cut into small pieces and washed with $500 \mu \mathrm{L}$ of lysis buffer containing $7 \mathrm{M}$ urea, $2 \mathrm{M}$ thiourea, 4\% CHAPS detergent, $65 \mathrm{mM}$ DTT, and $0.2 \%$ carrier ampholytes. The specimens were 
disrupted by sonication twice for $1 \mathrm{~min}$ at $0{ }^{\circ} \mathrm{C}$ and vortexed vigorously for approximately $2 \mathrm{~min}$. The lysates were centrifuged at $10,000 \mathrm{~g}$ for $3 \mathrm{~min}$ at $4{ }^{\circ} \mathrm{C}$. Protein concentration of the resulting supernatant was determined by the Bradford method [27]. The protein samples were stored in aliquots at $-80{ }^{\circ} \mathrm{C}$.

To optimize the experiments with 32 samples in triplicates, lymph node samples were pooled according to the presence or absence of tumor cells and according to the anatomic subsite, namely tongue, floor of the mouth, and larynx (Additional file 2). The 6 pools (A-F) combined equal amounts of protein from each sample, resulting in $100 \mu \mathrm{g}$ and $1500 \mu \mathrm{g}$ per pool for one-dimensional gel electrophoresis (1-DE) and two-dimensional gel electrophoresis (2-DE) gels, respectively.

\section{One-dimensional gel electrophoresis (1-DE)}

Two protein pools (E and F) of $3 \mathrm{~N} 0$ and $6 \mathrm{~N}+$ lymph nodes from larynx carcinomas were analyzed by 1-DE. Under reducing conditions, $100 \mu \mathrm{g}$ of each protein pool were denatured at $96{ }^{\circ} \mathrm{C}$ for $5 \mathrm{~min}$ in $5 \mathrm{X}$ loading buffer with $\beta$-mercaptoethanol and loaded on one-dimensional $12 \%$ resolving/5\% stacking sodium dodecyl sulfate (SDS) polyacrylamide gel (PAGE), according to Laemmli [28]. Electrophoresis was carried out on a vertical electrophoresis apparatus (SE 400 Vertical Unit, GE Healthcare, Uppsala, Sweden) at $120 \mathrm{~V}$. Proteins were detected by Coomassie Blue staining, and the molecular mass was estimated using molecular weight standard proteins of 14.4-97 kDa (LMW Calibration Kit for SDS Electrophoresis, GE Healthcare).

\section{Two-dimensional gel electrophoresis (2-DE)}

Three protein pools of $\mathrm{N} 0$ and three protein pools of $\mathrm{N}+$ lymph nodes from patients with tongue (pools A and B), floor of the mouth (pools $C$ and D) or larynx carcinomas (pools $\mathrm{E}$ and $\mathrm{F}$ ) were analyzed by $2-\mathrm{DE}$, according to de Marqui et al. [26], with modifications. Proteins were precipitated using ice-cold acetone $100 \%$, and centrifuged at 13,000 g for $5 \mathrm{~min}$ at $4{ }^{\circ} \mathrm{C}$. Aliquots containing approximately $1500 \mu \mathrm{g}$ of protein were diluted with rehydration buffer [ $8 \mathrm{M}$ urea, $2 \% \mathrm{w} / \nu$ CHAPS, $0.6 \% \mathrm{w} / \mathrm{v}$ DTT, $0.5 \% v / \mathrm{v}$ immobilized linear $\mathrm{pH}$ gradient (IPG) buffer $\mathrm{pH} 3-10$, trace of bromophenol blue] to a total volume of $250 \mu \mathrm{L}$ and loaded onto an IPG strip $(13 \mathrm{~cm}$, pH 3-10 L, GE Healthcare).

After isoelectric focusing/IEF (total of 26,500 V-hours at $20{ }^{\circ} \mathrm{C}, 50 \mathrm{~mA} /$ strip) on an IPGphor apparatus (GE Healthcare), IPG strips were incubated in the equilibration solution (6 M urea, $50 \mathrm{mM}$ Tris- $\mathrm{HCl} \mathrm{pH} \mathrm{8.8,30 \%} \mathrm{v/v} \mathrm{gly-}$ cerol, $2 \% \mathrm{w} / \mathrm{v}$ SDS, trace of bromophenol blue) containing $1 \% \mathrm{w} / \mathrm{v}$ DTT, followed by incubation in the same solution containing $2.5 \% \mathrm{w} / \mathrm{v}$ iodoacetamide instead of DTT. IPG strips were sealed on top of $12.5 \%$ SDS-polyacrylamide gel $0.5 \% \mathrm{w} / \mathrm{v}$ low-melting agarose in SDS running buffer.

Electrophoresis was performed in a Hoefer SE 600 Ruby vertical electrophoresis unit (GE Healthcare) at $15 \mathrm{~mA} /$ gel for $30 \mathrm{~min}$ and $30 \mathrm{~mA} /$ gel for $7 \mathrm{~h}$ at $10{ }^{\circ} \mathrm{C}$. The samples were run in triplicate and the LMW Calibration Kit was used as a molecular mass standard. After Coomassie blue staining, the gels were scanned using an ImageScanner (GE Healthcare) and the images were analyzed using the ImageMaster 2D Platinum software, version 6.0 (GE Healthcare). Gels from N0 and $\mathrm{N}+$ groups of each anatomical subsite were matched to a reference gel. Spot quantification was based on the spot volume as percentage of the total volume of all spots in the gel. For each anatomical subsite, differential image analysis was carried out by matching spots from gel triplicates of each group (N0 and $\mathrm{N}+$ ). Differences between groups were evaluated statistically by using the Student's $t$-test with $p<0.05$ as significant.

\section{In-gel protein digestion and mass spectrometry (MS)}

Sequential slices of 1-DE gels and differentially expressed protein spots from 2-DE gels were manually cut out from the gels. The samples were mixed with $50 \%$ acetonitrile (ACN)/25 mM ammonium bicarbonate solution and dehydrated with $\mathrm{ACN}$ for $15 \mathrm{~min}$. Acetonitrile was discarded and the gel pieces were dried in a vacuum centrifuge for $30 \mathrm{~min}$. Gel pieces were digested with trypsin and incubated for $24 \mathrm{~h}$ at $37^{\circ} \mathrm{C}$. Peptides were extracted with $1 \%$ trifluoroacetic acid (TFA) for $12 \mathrm{~h}$ and $1 \%$ TFA $/ 50 \%$ ACN for $2 \mathrm{~h}$. The supernatants were mixed and concentrated in a vacuum centrifuge to approximately $5-10 \mu \mathrm{L}$.

Digested samples from 1-DE gels were applied to a C18 $(100 \mu \mathrm{m}$ X $100 \mathrm{~mm})$ RP-nanoUPLC (nanoAcquity, Waters, Milford, MA, USA) coupled with a Q-TOF (Quadrupole Ion Trap - Time of Flight) Ultima mass spectrometer (Waters) with nano-electrospray source at a flow rate of $0.6 \mu \mathrm{L} / \mathrm{min}$. The gradient condition was developed with $0-50 \%$ acetonitrile in $0.1 \%$ formic acid for $60 \mathrm{~min}$. The instrument was operated in the top three' mode and the spectra were acquired using the MassLynx software version 4.1 (Waters). The raw data files were processed to peak list with the Mascot Distiller software, version 2.2.1.0 (Matrix Science, London, UK). Mascot search results were exported to Scaffold software (version 3.06, Proteome Software Inc., Portland, OR, USA) for validation. Protein and peptide identification probabilities were set up at $>95 \%$, with one minimum peptide. The samples were grouped in metastatic and non-metastatic, the spectral counts were normalized and proteins with a fold change $\geq 2.0$ were considered to be differentially expressed. Fold change was calculated by Scaffold software (according to [29]). 
After trypsin digestion, the peptide samples from 2-DE gels were placed into matrix solution $(10 \mathrm{mg} / \mathrm{mL} \alpha$-cyano4-hydroxycinnamic acid, $0.1 \% v / \mathrm{v}$ TFA in $50 \% \mathrm{v} / \mathrm{v}$ ACN) in a 1:1 (v:v) ratio, spotted on a stainless steel sample plate and analyzed by a MALDI-Q-TOF (Matrix Assisted Laser Desorption Ionization - Quadrupole Ion Trap - Time of Flight) Premier mass spectrometer (Waters). Mascot Daemon (version 2.2.0, Matrix Science) was used to search the NCBI non-redundant database with the parameters: enzyme, trypsin; allowed number of missed cleavages, 1; fixed modification, carbamidomethylation on cysteine; variable modification, oxidation on methionine; peptide tolerance, $0.1 \mathrm{Da}$; MS/MS tolerance, $0.1 \mathrm{Da}$; monoisotopic masses.

\section{Metabolic pathways, associated ontologies and expression data} The set of genes encoding differentially expressed proteins was imported into HNdb [30], a head and neck database that provides information on genes and proteins involved in head and neck squamous cell carcinoma, covering data on genomics, transcriptomics, proteomics, literature citations and also cross-references of external databases. Using this database, the genes were linked to KEGG [31] metabolic pathways, associated ontologies [32], and microarray data [33].

The set of genes was also functionally clustered using DAVID [34, 35], a database for annotation, visualization and integrated discovery. The one-tail Fisher Exact Probability Value was used for gene-enrichment analysis, and Bonferroni and Benjamini-Hochberg corrected $p$-values less than 0.05 were considered significant.

\section{Immunodetection}

In order to validate the proteomic findings, a literature search was performed to select candidate targets showing an unclear role in head and neck tumorigenesis or involved in the development and progression of head and neck neoplasms but never evaluated in their lymph node metastasis. Using these criteria, two proteins (epidermaltype fatty acid-binding protein or E-FABP, and annexin A1 or ANXA1) were selected to be validated.

\section{Western blot}

The expression of E-FABP was analyzed by Western blot in a subset of 22 individual samples (11 N0 and $11 \mathrm{~N}+$ lymph nodes from 8 tongue, 8 floor of the mouth and 6 larynx carcinomas). The antibodies used were polyclonal primary anti-E-FABP (ab37267, Abcam, Cambridge, MA, USA) diluted 1:500, and monoclonal primary anti- $\beta$-actin antibody (A1978 Sigma-Aldrich, Saint Louis, MO, USA) diluted 1:5000. In brief, protein samples $(10 \mu \mathrm{g})$ were subjected to SDS-PAGE (12\% resolving gel with 5\% stacking gel) under denaturing conditions at $120 \mathrm{~V}$ for 120 min, using a Mini-Protean 3 Cell Electrophoresis
System (BioRad, Hercules, CA, USA). The molecular weight ladder was the PageRuler ${ }^{\mathrm{Tm}}$ Prestained Protein Ladder (SM0671, Fermentas Life Sciences, Vilnius, Lithuania).

Samples were transferred electrophoretically ( $90 \mathrm{~V}$ for $90 \mathrm{~min}$ ) to polyvinylidene difluoride (PVDF) membranes (Immobilon-P Membrane, Millipore, Bedford, MA, USA) by using transfer buffer ( $25 \mathrm{mM}$ Tris, $0.2 \mathrm{M}$ glycine, $20 \%$ $v / \mathrm{v}$ methanol). Antibodies were detected using Western Breeze chromogenic system (Invitrogen, Carlsbad, CA, USA) and the blots were then scanned and analyzed using a Kodak Gel Logic 2200 Digital Imaging System (Carestream Health, Rochester, NY, USA).

\section{Immunohistochemistry}

Immunohistochemical analysis of a tissue microarray (TMA) with duplicate tissue cores of 65 primary oral squamous cell carcinoma samples was carried out by a polymer-based immunohistochemistry method using rabbit polyclonal antibody anti-E-FABP (ab37267), at a dilution of 1:500. Nine tissue slides containing archival formalin-fixed, paraffin-embedded tissue (FFPE) sections of surgical margins were used to establish a cut off value level for positivity. After deparaffinization and rehydration in xylene and graded ethanol, the slides were immersed in $10 \mathrm{mM}$ citrate buffer $(\mathrm{pH}$ 6.0) and heated in a water bath $\left(97{ }^{\circ} \mathrm{C}, 20 \mathrm{~min}\right)$ for antigen epitope retrieval. Endogenous peroxidase activity was blocked with methanol containing 3\% hydrogen peroxide for $30 \mathrm{~min}$. Specimens were incubated overnight with the primary antibody in a humidity-controlled chamber. The sections were washed twice with PBS and Tween $0.25 \%$ at room temperature. Immune complexes were subsequently treated using EnVision+Dual Link System-HRP (K4061, DAKO, Fisher Scientific, Hampton, NH, USA), and DAB (3,3'-diaminobenzidine) in chromogen solution (K3468; DAKO, Fisher Scientific). Counterstaining was performed with Mayer's hematoxylin. Nuclear and cytoplasmatic staining of the epithelial cells was considered specific.

Percentage of positive cells in each TMA spot was scored as follows: 0 or negative (not detectable or detectable in less than $5 \%$ of tumor cells), 1 (labeling of more than $5 \%$ and less than $10 \%$ of tumor cells), 2 (labeling of more than $10 \%$ and less than $50 \%$ of tumor cells), 3 (labeling of more than $50 \%$ and less than $75 \%$ of tumor cells), 4 (widely and highly expressed in more than $75 \%$ of the tumor cells), at $\times$ 400 magnification. The intensity of immunoreaction was scored as negative (0), mild (1), moderate (2) and intense (3). The percentage of positive tumor cells and the staining intensity then were multiplied to produce an E-FABP score for each case. Cases with a final score $>9.4$ (the average score from normal tissue) were defined as positive.

Immunohistochemical analysis of 14 lymph node specimens from patients with C02, C04 and C32 tumors was also performed to investigate the expression of annexin 
A1. Two-micrometer FFPE sections were processed by deparaffinization, rehydration and antigen epitope retrieval, as described above. Endogenous peroxidase and non-specific epitopes were blocked with $3 \%$ hydrogen peroxide and $5 \%$ bovine serum albumin in phosphate-buffered saline (BSA-PBS) for $30 \mathrm{~min}$, respectively. The slides were then incubated overnight at $4{ }^{\circ} \mathrm{C}$ with rabbit polyclonal antiANXA1 (71-3400, Thermo Fisher Scientific, Waltham, MA, USA) at a dilution of 1:2000, in 1\% BSA. Some sections were incubated with $1 \%$ BSA instead of the primary antibody to provide a negative control of the reaction. After washing, sections were incubated with the secondary biotinylated antibody (959943-B, Thermo Fisher Scientific). Positive staining was detected using a peroxidase-conjugated streptavidin complex and the color was developed using DAB substrate (002014, Thermo Fisher Scientific). Finally, sections were counterstained with hematoxylin and mounted. ANXA1 immunostaining was evaluated by densitometric analysis conducted using an Axioskop 2-Mot Plus Microscope and AxioVision 4.8 software (Carl Zeiss, Jena, Germany) on an arbitrary scale from 0 to 255. Data were expressed as mean \pm standard error.

\section{Results}

\section{Casuistic}

Of the 32 lymph node samples evaluated by $1-\mathrm{DE} / \mathrm{MS}$, 2-DE/MS, 12 were derived from patients with N0 and 20 with $\mathrm{N}+$ tumors classified as: 10 tongue, 13 floor of the mouth and 9 larynx carcinomas (C02, C04, C32, respectively). The samples were combined in six pools and analyzed using 1-DE and/or 2-DE and mass spectrometry (Additional file 2). The mean age of the patients was 60.1 years (range, 45-79 years), and the male/female sex ratio was 9.7:1. Most patients were smokers or former smokers (28/32) and had a history of chronic alcohol consumption (29/32) (Additional file 1).

\section{Proteomic approaches}

One- and two-dimensional gel electrophoresis (1-DE and 2-DE)

The 1-DE data validated by Scaffold software allowed the identification of 39 differentially expressed proteins ( $\geq 2.0$-fold change) between N0 and N+ lymph nodes, with over 99\% confidence (as per the Scaffold algorithm, at least one unique peptide per protein) (Table 1). Using these parameters, the false discovery rate (FDR) for protein identification was $0.2 \%$. The 2-DE analysis revealed 22 differentially expressed proteins between metastatic and non-metastatic lymph nodes (Student's t test $p<0.05$ ). Fourteen proteins were overexpressed and eight underexpressed in metastatic samples compared with non-metastatic ones (Table 2, Fig. 1, Additional file 3). Nine differentially expressed proteins were detected by both 1-DE and 2-DE (Apo-AI, CA-I, GSTP1-1, HspB1, hemoglobin subunit delta, CK1, profilin-1, TIM, protein S100-A9), four of them (Apo-AI, GSTP1-1, HspB1, CK1) overexpressed by $2-\mathrm{DE}$ and underexpressed by 1-DE (Tables 1 and 2). Therefore, a total of 52 differentially expressed proteins were identified. Some of them exhibited a diverse 2-DE profile in metastasis of tongue, floor of the mouth and larynx carcinomas. For example, Apo-AI only showed differential expression in $\mathrm{N}+$ lymph nodes of floor of the mouth tumors, and calreticulin and PDI in N+ lymph nodes of larynx carcinomas. Differences between $\mathrm{C} 02$ and C04, which are derived from the same anatomical subsite (oral cavity), were also observed, such as hemoglobin subunit delta, endoplasmin, LAP-3, Apo-AI, Ig gamma and kappa chains, and CK1 (Table 2).

\section{Metabolic pathways, associated ontologies and expression data}

Clustering the set of 52 differentially expressed genes using DAVID, 16 annotation clusters were obtained, 6 of them with Bonferroni and Benjamini-Hochberg corrected $p$-values $<0.05$ (Additional file 4). These clusters were related to regulation of cell-cell adhesion, cellular oxidant detoxification, response to reactive oxygen species, and membrane organization. When analyzed individually by $\mathrm{HNdb}$ tools, over and underexpressed proteins showed activities expected for lymph nodes containing metastatic cells, many being associated with angiogenesis, apoptosis, cell growth, cell migration, and development processes (Tables 3 and 4).

Positive scores for gene-to-HNSCC association determined by HNdb hypergeometric test were referred to $30 / 52$ genes encoding these proteins (Additional file 5). Seven out of 52 genes (GSTP1, HSP90B1, HSPB1, PFN1, RAP1A, SFN, YWHAZ) were assigned to KEGG pathways in cancer, cell migration and cell cycle, and in signaling networks involved in proliferation, cellular motility, apoptosis, cell adhesion, angiogenesis and genetic integrity.

\section{Immunodetection}

A protein related to invasive phenotype (E-FABP) and a potential cancer marker showing an unanticipated expression profile (annexin A1) were selected for validation by Western blotting and/or immunohistochemical assay. As expected, Western blot analysis revealed high levels of E-FABP in most $\mathrm{N}+$ lymph nodes (10/11) when compared with N0 samples (0/11) (Fig. 2), which was confirmed by pixel density quantification using Image $\mathrm{J}$ software. In immunohistochemical assays, 41/65 primary tumor samples were considered positive for E-FABP (Fig. 3). Fisher's exact test was used to estimate statistical difference between E-FABP positivity and clinicopathological parameters. There was no significant association between tumor size $(p=0.61)$, nodal metastasis $(p=0.80)$, pathologic 
Table 1 Under and overexpressed proteins identified by one-dimensional gel electrophoresis (1-DE) in metastatic ( $\mathrm{N}+)$ and non-metastatic (NO) lymph nodes from laryngeal SCC patients. Proteins were separated by one-dimensional gel electrophoresis and identified by Q-TOF MS and Scaffold software according to quantitative value. Thirty-nine proteins with a fold change of at least 2.0 were considered with differential abundance between the categories

\begin{tabular}{|c|c|c|c|c|c|c|}
\hline \multirow[t]{2}{*}{ Protein name } & \multirow{2}{*}{$\begin{array}{l}\text { Gene } \\
\text { symbol }\end{array}$} & \multirow{2}{*}{$\begin{array}{l}\text { UniProt } \\
\text { accession }\end{array}$} & \multicolumn{2}{|c|}{ Quantitative value } & \multirow{2}{*}{$\begin{array}{l}\text { Fold change } \\
\mathrm{N}+/ \mathrm{NO}\end{array}$} & \multirow[t]{2}{*}{$\mathrm{N}+$} \\
\hline & & & $\mathrm{N}+$ & No & & \\
\hline Actin, cytoplasmic 1 & $A C T B$ & P60709 & 1 & 8 & 0.1 & Down \\
\hline Serum albumin & $A L B$ & P02768 & 2 & 14 & 0.1 & Down \\
\hline Apolipoprotein A-I & $A P O A 1$ & P02647 & 0 & 10 & $<2.0$ & Down \\
\hline Rho GDP-dissociation inhibitor 1 & ARHGDIA & P52565 & 0 & 2 & $<2.0$ & Down \\
\hline Rho GDP-dissociation inhibitor 2 & $A R H G D I B$ & P52566 & 0 & 4 & $<2.0$ & Down \\
\hline Flavin reductase (NADPH) & $B L V R B$ & P30043 & 0 & 3 & $<2.0$ & Down \\
\hline Carbonic anhydrase 1 & CA1 & P00915 & 0 & 2 & $<2.0$ & Down \\
\hline Coactosin-like protein & COTL1 & Q14019 & 0 & 2 & $<2.0$ & Down \\
\hline Glyceraldehyde-3-phosphate dehydrogenase & GAPDH & P04406 & 1 & 2 & 0.5 & Down \\
\hline Glutathione S-transferase P & GSTP1 & P09211 & 0 & 2 & $<2.0$ & Down \\
\hline Hemoglobin subunit alpha & $H B A 1 / H B A 2$ & P69905 & 0 & 28 & $<2.0$ & Down \\
\hline Hemoglobin subunit beta & $H B B$ & P68871 & 0 & 10 & $<2.0$ & Down \\
\hline Hemoglobin subunit delta & $H B D$ & P02042 & 0 & 17 & $<2.0$ & Down \\
\hline Histone $\mathrm{H} 2 \mathrm{~A}$ type $1-\mathrm{A}$ & HIST1H2AA & Q96QV6 & 0 & 2 & $<2.0$ & Down \\
\hline Histone $\mathrm{H} 2 \mathrm{~B}$ type $1-\mathrm{C} / \mathrm{E} / \mathrm{F} / \mathrm{G} / \mathrm{I}$ & HIST1H2BG & P62807 & 0 & 3 & $<2.0$ & Down \\
\hline Histone H3.1 & HIST1H3A & P68431 & 0 & 4 & $<2.0$ & Down \\
\hline Heat shock protein beta-1 & HSPB1 & P04792 & 0 & 3 & $<2.0$ & Down \\
\hline Keratin, type II cytoskeletal 1 & KRT1 & P04264 & 0 & 3 & $<2.0$ & Down \\
\hline Keratin, type I cytoskeletal 9 & KRT9 & P35527 & 0 & 2 & $<2.0$ & Down \\
\hline Myosin light polypeptide 6 & MYL6 & P60660 & 0 & 2 & $<2.0$ & Down \\
\hline Protein deglycase DJ-1 & PARK7 & Q99497 & 0 & 3 & $<2.0$ & Down \\
\hline Profilin-1 & PFN1 & P07737 & 0 & 5 & $<2.0$ & Down \\
\hline Peptidyl-prolyl cis-trans isomerase A & PPIA & P62937 & 1 & 6 & 0.2 & Down \\
\hline Peroxiredoxin-1 & PRDX1 & Q06830 & 1 & 6 & 0.2 & Down \\
\hline Peroxiredoxin-2 & PRDX2 & P32119 & 0 & 5 & $<2.0$ & Down \\
\hline Peroxiredoxin-6 & PRDX6 & P30041 & 0 & 2 & $<2.0$ & Down \\
\hline Proteasome subunit beta type- 5 & PSMB5 & P28074 & 0 & 2 & $<2.0$ & Down \\
\hline Ras-related protein Rab-10 & $R A B 10$ & P61026 & 1 & 2 & 0.5 & Down \\
\hline Ras-related protein Rab-5B & $R A B 5 B$ & P61020 & 0 & 2 & $<2.0$ & Down \\
\hline Ras-related protein Rap-1A & RAPIA & P62834 & 0 & 2 & $<2.0$ & Down \\
\hline Transgelin-2 & TAGLN2 & P37802 & 0 & 2 & $<2.0$ & Down \\
\hline Triosephosphate isomerase & TPl1 & P60174 & 2 & 11 & 0.2 & Down \\
\hline 14-3-3 protein beta/alpha & $Y W H A B$ & P31946 & 0 & 7 & $<2.0$ & Down \\
\hline 14-3-3 protein zeta/delta & YWHAZ & P63104 & 3 & 10 & 0.3 & Down \\
\hline Annexin A1 & ANXA1 & P04083 & 4 & 0 & $>2.0$ & Up \\
\hline Keratin, type I cytoskeletal 13 & KRT13 & P13646 & 3 & 0 & $>2.0$ & Up \\
\hline Keratin, type II cytoskeletal 6A & KRT6A & P02538 & 4 & 0 & $>2.0$ & Up \\
\hline Periostin & POSTN & Q15063 & 2 & 0 & $>2.0$ & Up \\
\hline Protein S100-A9 & S100A9 & P06702 & 10 & 0 & $>2.0$ & Up \\
\hline
\end{tabular}


Table 2 Under and overexpressed proteins identified by two-dimensional gel electrophoresis (2-DE) in metastatic ( $\mathrm{N}+)$ and non-metastatic (N0) lymph nodes from oral cavity SCC patients. Proteins were separated by two-dimensional electrophoresis and identified by MALDI-Q-TOF MS/MS. Twenty-two proteins were considered with differential abundance between the categories (Student's t test $p<0.05$ ). C02, C04, C32 columns correspond to pools from tongue (pools A and B), floor of the mouth (pools C and D) and larynx carcinomas (pools $\mathrm{E}$ and F), respectively. N+/NO: abundance ratio

\begin{tabular}{|c|c|c|c|c|c|c|c|c|c|c|c|c|}
\hline Protein name & $\begin{array}{l}\text { Gene } \\
\text { symbol }\end{array}$ & $\begin{array}{l}\text { UniProt } \\
\text { accession }\end{array}$ & $\mathrm{pl}$ & Mass & $\begin{array}{l}\text { Sequence } \\
\text { coverage (\%) }\end{array}$ & Score & $\begin{array}{l}\text { Queries } \\
\text { matched }\end{array}$ & Area $^{a}$ & $\begin{array}{l}\mathrm{C} 02 \\
\mathrm{~N}+/ \mathrm{NO}\end{array}$ & $\mathrm{CO4}$ & C32 & $\mathrm{N}+$ \\
\hline Carbonic anhydrase 1 or CA-I & CA1 & P00915 & 6.65 & 28,620 & 16 & 116 & 3 & VII & 0.4402 & 0.2033 & 0.2971 & Down \\
\hline Calreticulin or CRP55 & CALR & P27797 & 4.29 & 48,283 & 9 & 167 & 3 & IX & & & 0.6211 & Down \\
\hline Hemoglobin subunit delta & $H B D$ & P02042 & 7.97 & 16,028 & 19 & 64 & 2 & IV & & 0.3906 & 0.1063 & Down \\
\hline $\begin{array}{l}\text { Heat shock protein } 90 \mathrm{kDa} \text { beta } \\
\text { member } 1 \text { or endoplasmin }\end{array}$ & HSP9OB1 & P14625 & 4.76 & 92,696 & 4 & 69 & 3 & I & 0.4010 & & 0.5364 & Down \\
\hline Cytosol aminopeptidase or LAP-3 & $\angle A P 3$ & P28838 & 6.29 & 53,006 & 4 & 71 & 3 & IX & 0.4514 & & 0.6685 & Down \\
\hline Protein disulfide-isomerase or PDI & $P 4 H B$ & P07237 & 4.76 & 57,480 & 8 & 201 & 4 & IX & & & 0.6616 & Down \\
\hline Profilin-1 & PFN1 & P07737 & 8.48 & 15,085 & 10 & 50 & 2 & IV & 0.3568 & 0.4595 & 0.6419 & Down \\
\hline Triosephosphate isomerase or TIM & TPI1 & P60174 & 6.51 & 26,807 & 8 & 51 & 1 & $\mathrm{Vl}$ & 0.5020 & 0.3262 & 0.3373 & Down \\
\hline $\begin{array}{l}\text { Aldo-keto reductase family } 1 \\
\text { member B10 or ARL-1 }\end{array}$ & AKR1B10 & O60218 & 7.12 & 36,226 & 12 & 149 & 3 & $\|$ & 3.7339 & 2.2564 & & Up \\
\hline Apolipoprotein A-I or Apo-Al & $A P O A 1$ & P02647 & 5.56 & 30,759 & 11 & 104 & 3 & $\mathrm{Vl}$ & & 1.5333 & & Up \\
\hline Cystatin-B or CPI-B & CSTB & P04080 & 7.90 & 11,224 & 24 & 64 & 2 & $X I$ & 2.0971 & 1.9614 & & Up \\
\hline $\begin{array}{l}\text { Fatty acid-binding protein, epidermal } \\
\text { or E-FABP }\end{array}$ & FABP5 & Q01469 & 6.84 & 15,366 & 18 & 94 & 2 & VIII & 4.0016 & 7.4081 & 5.5954 & Up \\
\hline Glutathione S-transferase P or GSTP1-1 & GSTP1 & P09211 & 5.44 & 23,438 & 12 & 78 & 2 & $\mathrm{Vl}$ & 2.3289 & 4.0385 & 2.9731 & Up \\
\hline Heat shock protein beta-1 or HspB1 & HSPB1 & P04792 & 5.98 & 22,826 & 20 & 105 & 3 & III & 3.2028 & 4.1256 & 4.5202 & Up \\
\hline Ig gamma-1 chain $C$ region & IGHGI & P01857 & 8.46 & 36,596 & 9 & 71 & 2 & $x$ & 4.1259 & & 4.3046 & Up \\
\hline Ig kappa chain C region & IGKC & P01834 & 7.55 & 26,077 & 14 & 48 & 2 & $\mathrm{VII}$ & & 2.5279 & 2.1303 & Up \\
\hline Keratin, type II cytoskeletal 1 or CK1 & KRT1 & P04264 & 8.16 & 66,018 & 4 & 82 & 2 & VII & & 1.7525 & 2.0958 & Up \\
\hline Galectin-1 or Gal-1 & LGALS1 & P09382 & 5.34 & 14,917 & 8 & 54 & 1 & V & 1.8654 & 2.2229 & 1.4698 & Up \\
\hline Galectin-7 or Gal-7 & $L G A L S 7 B$ & P47929 & 7.00 & 14,992 & 19 & 73 & 2 & VIII & 6.2867 & 2.5605 & 2.7244 & Up \\
\hline Protein S100-A7 or psoriasin & S100A7 & P31151 & 6.26 & 11,433 & 34 & 103 & 3 & VIII & 6.4075 & 9.3486 & 5.3993 & Up \\
\hline Protein S100-A9 or calgranulin-B & S100A9 & P06702 & 5.71 & 13,291 & 42 & 100 & 3 & VIIII & 4.7500 & 5.9737 & 4.9505 & Up \\
\hline 14-3-3 protein sigma or stratifin & SFN & P31947 & 4.64 & 27,874 & 15 & 98 & 3 & III & 13.4829 & 7.3989 & 27.6468 & Up \\
\hline
\end{tabular}

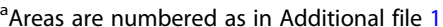

TNM classification $(p=0.37)$, pathological grade $(p=0.20)$, lymphatic, and perineural invasion $(p=1.00 ; p=0.36)$. Overall survival rate was compared with the expression of FABP5 using the Kaplan-Meier method, and the $P$ value for the survival curve, determined by the log-rank test, was not statistically significant in the survival rates between positive and negative tumors $(p=0.88)$.

Immunohistochemical analysis of ANXA1 was carried out on metastatic and non-metastatic lymph node samples. Constitutive ANXA1 expression was observed in the subcapsular sinus of N0 lymph nodes (Fig. 4a). In the N+ samples, its expression was increased, especially in the loose conjunctive tissue, which constitutes the subcapsular sinus, above the external cortex of the lymph node. In these metastatic samples, epithelial cells showed a more intense cytoplasmatic expression of ANXA1 compared to control biopsies (Fig. 4b). No immunostaining was detected in the negative control (Fig. 4c).

ANXA1 was not validated by Western blot. Due to the limited amount of protein from lymph node samples, the detection by immunohistochemistry was prioritized, since it is a more sensitive and specific assay and can be performed on paraffin-embedded sections.

\section{Discussion}

In the present study, we investigated the proteomic profile of lymph node metastasis from squamous cell carcinomas of tongue, floor of the mouth and larynx, by using one- and two-dimensional electrophoresis and mass spectrometry analysis. Fifty-two proteins were differentially expressed in metastatic compared with nonmetastatic lymph nodes analyzed by $1-\mathrm{DE}$ and 2-DE. 

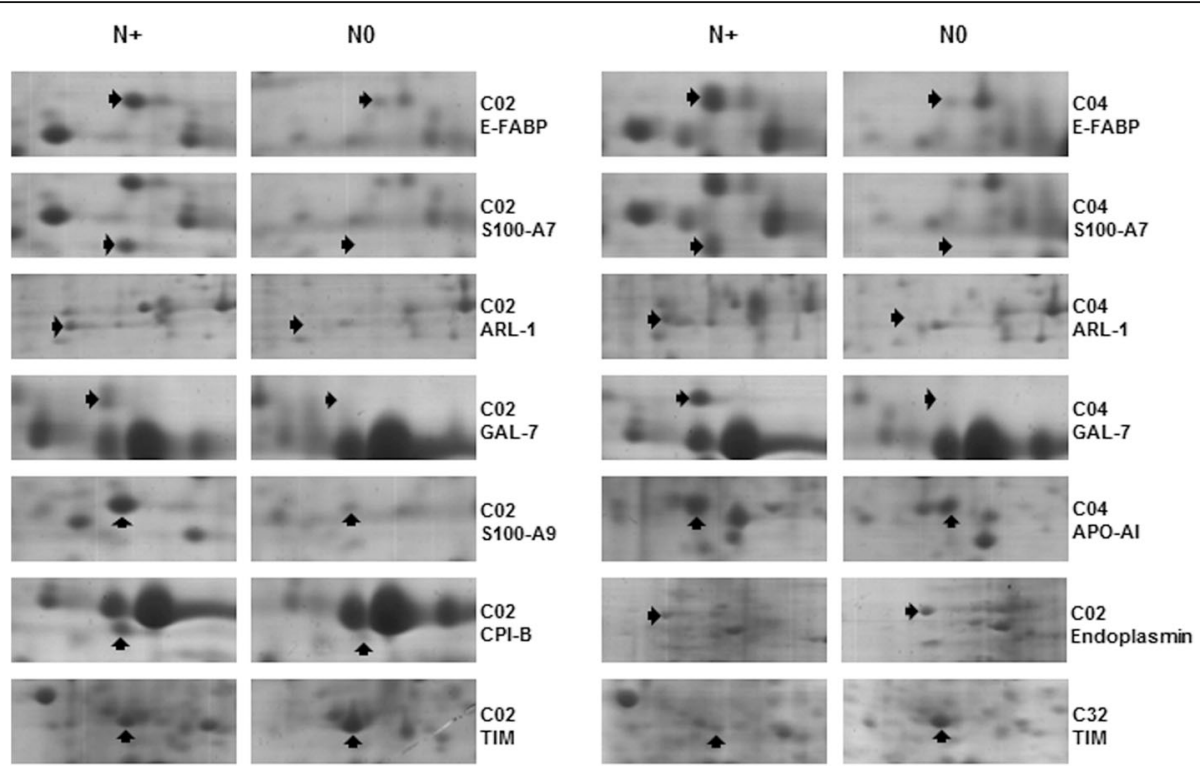

Fig. 1 Partial 2-DE gel images of differentially expressed proteins in metastatic ( $\mathrm{N}+$ ) and non-metastatic (NO) lymph nodes of HNSCC. Anatomical subsites - C02 (tongue), floor of the mouth (C04) and larynx carcinomas (C32) - and protein symbols/names are provided to the right of each panel. Over and underexpressed proteins are indicated with arrows

Western blot and/or immunohistochemical analysis confirmed the results for two representative proteins (E-FABP and annexin A1). Although the performance of 1 -DE was better than that of $2-\mathrm{DE}$, several recent studies using 2-DE technique present consistent results [36-40] and show that it is still an important top-down analytical approach [41]. Anyhow, 1-DE is also unable to completely resolve complex mixtures of proteins.

Some of the over and underexpressed proteins may play an important role in the head and neck tumorigenesis and metastatization processes. For example, aldo-keto reductase ARL-1 is a potential biomarker for non-small cell lung cancer of smokers [42] and, therefore, may be involved in the pathogenesis of tobacco-related cancers [43], including HNSCCs. Other proteins have already been associated with HNSCC by several authors [44-46] and by our group, particularly annexin A1 [47, 48], fatty acid-binding protein E-FABP $[49,50]$, heat shock protein beta-1 [51, 52], galectin-1 [53, 54], glutathione S-transferase P $[55,56]$, keratin, type I cytoskeletal 13 [57, 58], peptidyl-prolyl cis-trans isomerase A [59, 60], periostin [61], protein deglycase DJ-1 [62, 63], protein S100A7 [64, 65] and Ras-related protein RAP-1A [66]. In fact, the genes encoding some of these proteins showed the highest scores for gene-to-HNSCC association determined by HNdb hypergeometric test, namely FABP5, S100A7, ANXA1, LGALS1, PARK7, GSTP1, with scores ranging from 1.88 to 83 . The expression pattern of these proteins was also evaluated using The Human Protein Atlas (https://www.proteinatlas.org), a public database containing protein expression information based on approximately 700 antibodies combined with transcriptomics data from The Cancer Genome Atlas - TCGA (average fragments per kilobase of transcript per million mapped reads - FPKM) [67]. Because Protein Atlas has very few samples analyzed by immunohistochemistry and joins different subsites of head and neck carcinomas, the data showed low concordance with our findings. Otherwise, our findings showed higher concordance with the average FPKM values, especially for upregulated proteins. Similarly to what our group and other authors $(44,45,81)$ observed for ANXA1/annexin A1 in primary tumors, Protein Atlas and TCGA refer a low expression of this protein in primary HNSCC.

Some differences were observed between lymph node samples from dissimilar anatomic subsites, which support a molecular heterogeneity for HNSCC metastasis, also previously reported by us for the primary tumors [68]. The differences in expression of, for example, APO-AI, calreticulin, CK1, endoplasmin, LAP-3, PDI, may affect tumor progression and drug response because these proteins are involved in signaling, cell proliferation, response to hypoxia and oxidative stress.

In regard to the metastasis environment, many questions remain. What proteins are predictive biomarkers for regional metastasis in HNSCC? What features were previously selected and expressed in cells leaving the primary tumor? After arriving in the lymph nodes, what would be the new challenge for tumor cells? Tentative answers to these questions may be exemplified by the findings we 
Table 3 Information on biological processes based on Gene ontology. Up-regulated proteins identified by proteomic analysis of positive lymph node samples. Proteins are referenced by their HGNC gene symbol

\begin{tabular}{|c|c|}
\hline Biological process & Up-regulated proteins $^{a}$ \\
\hline Angiogenesis & HSPB1 \\
\hline Apoptosis & LGALS1, S100A9, SFN \\
\hline Anti-apoptosis & ANXA1, GSTP1, HSPB1 \\
\hline Autophagy & S100A9 \\
\hline \multicolumn{2}{|l|}{ Cell adhesion } \\
\hline Cell-cell adhesion & APOA1, POSTN \\
\hline \multicolumn{2}{|l|}{ Cell communication } \\
\hline Signaling & $\begin{array}{l}\text { ANXA1, APOA1, HSPB1, IGHG1, IGKC, } \\
\text { LGALS1, S100A7, S100A9, SFN }\end{array}$ \\
\hline Cell-cell signaling & S100A9 \\
\hline \multicolumn{2}{|l|}{ Cell growth } \\
\hline $\begin{array}{l}\text { Positive regulation of cell } \\
\text { growth }\end{array}$ & S100A9 \\
\hline \multicolumn{2}{|l|}{ Cell migration or movement } \\
\hline Cell motility & ANXA1, HSPB1, S100A9 \\
\hline Cytoskeleton organization & KRT13, S100A9 \\
\hline \multicolumn{2}{|l|}{ Developmental process } \\
\hline System development & GSTP1, POSTN \\
\hline Cell differentiation & ANXA1 \\
\hline Epidermis development & FABP5, S100A7, SFN \\
\hline Metabolic process & AKR1B10, APOA1, FABP5, GSTP1 \\
\hline Protein metabolic process & APOA1, CSTB \\
\hline Lipid metabolic process & APOA1, FABP5 \\
\hline Protein modification process & GSTP1, SFN \\
\hline Response to stimulus & ANXA1, HSPB1 \\
\hline Defense response & KRT6A, S100A7, S100A9 \\
\hline Inflammatory response & ANXA1, APOA1, S100A9 \\
\hline Immune response & APOA1, IGHG1, IGKC \\
\hline Response to ROS & GSTP1, S100A7 \\
\hline Transcription & S100A9, SFN \\
\hline Translation & HSPB1 \\
\hline Transport & APOA1 \\
\hline
\end{tabular}

a Name of up-regulated proteins:AKR1B10 Aldo-keto reductase family 1 member B10, ANXA1 Annexin A1, APOA1 Apolipoprotein A-I, CSTB Cystatin-B, FABP5 Fatty acid-binding protein, epidermal, GSTP1 Glutathione S-transferase $P$, HSPB1 Heat shock protein beta-1, IGHG1 Ig gamma-1 chain C region, IGKC lg kappa chain C region, KRT6A Keratin, type II cytoskeletal 6A, KRT13 Keratin, type I cytoskeletal 13, LGALS1 Galectin-1, POSTN Periostin, S100A7 Protein S100A7, S100A9 Protein S100A9, SFN 14-3-3 protein sigma

obtained for galectin-1 and psoriasin. These proteins have been shown to be associated with hypoxia [69-71], a common adverse condition faced by metastatic, as well as primary tumor cells. The findings of Chaudary and Hill [72] reinforce the idea that 'hypoxia-related' factors regulate lymph node metastasis under intermittent hypoxic conditions. According to these authors, lymphatic vessels occur more often only in the periphery of tumors; these regions of acute hypoxia may stimulate the cells to spread through lymphatic vessels, leading to increased lymph node metastasis [73].

Concerning epidermal-type fatty acid-binding protein (E-FABP), our proteomic approach detected that this member of the fatty acid-binding protein family is overexpressed in lymph node metastasis, a result supported by Western blotting experiments in tumor samples. These findings are somewhat in disagreement with those of Uma and collaborators [49], who reported a downregulation of FABP5 in metastatic lymph nodes compared to the corresponding primary tumors. These discordant results can be explained by the fact that Uma's group analyzed transcripts while the present work evaluated gene expression at the protein level. General correlations between the levels of RNA and the corresponding proteins have been observed, but even with stringent methods partial or reverse correlations are also detected, probably due to regulatory mechanisms or variable accuracy on the RNA level, as reviewed by Gry and collaborators [74].

However, similarly to our findings, FABP5/E-FABP overexpression in HNSCC lymph node metastasis has been observed by others $[50,75]$. Increased serum reactivity to E-FABP in HNSCC patients [75], and association of higher E-FABP levels with HPV-positive oral and oropharyngeal carcinomas [76] and with cell proliferation and invasiveness [50] have also been found. In respect to HPV status, our group have previously studied a cohort of more than 1000 HNSCC cases to determine the serological response to oncoproteins of HPV16 and 400 HNSCC cases to investigate HPV16 DNA in tumor samples. The results showed a low prevalence of HPV16 DNA and HPV16 E6 and E6/E7 antibodies in oral and larynx carcinomas [77]. Given that the patients analyzed by the present study represent a subset included in this previous report, we can hypothesize that FABP5/E-FABP findings are not related to the HPV status in our cohorts. Regarding other neoplasms, a high expression of E-FABP was detected in tumor tissues, serum [78] and urinary extracellular vesicles from patients with high prostate cancer [79] as well as in cervical cancer tissues, and significantly correlated with lymph node metastasis, lymphovascular space invasion, stage and tumor size [80].

E-FABP is a cytosolic lipid binding protein of epidermal cells that uptakes, binds and transports long chain fatty acids to cell organelles. The study of Bao et al. [81] demonstrated that E-FABP overexpression results in an increase in the levels of fatty acid uptake and transport into the nucleus, and also in tumor-promoting activity. The authors suggested that such tumorigenic activity is due to the activation of the nuclear receptor peroxisome 
Table 4 Information on biological processes based on Gene ontology. Down-regulated proteins identified by proteomic analysis of positive lymph node samples. Proteins are referenced by their HGNC gene symbol

\begin{tabular}{|c|c|}
\hline Biological process & Down-regulated proteins ${ }^{a}$ \\
\hline Apoptosis & CALR, YWHAB \\
\hline Regulation of apoptosis & $\mathrm{HBA} 1 / 2, \mathrm{HBB}, \mathrm{P} 4 \mathrm{HB}, \mathrm{PRDX} 2$ \\
\hline Anti-apoptosis & ALB, ARHGDIA, HSP90B1, PARK7, PSMB5, YWHAZ \\
\hline Cell adhesion & ARHGDIA, ARHGDIB \\
\hline \multicolumn{2}{|l|}{ Cell cycle } \\
\hline Arrest & CALR, PSMB5 \\
\hline \multicolumn{2}{|l|}{ Cell communication } \\
\hline Signaling & $\begin{array}{l}\text { ACTB, ARHGDIA, ARHGDIB, CALR, HIST1H3A, HSP90B1, MYL6, PARK7, PSMB5, } \\
\text { RAP1A, YWHAB, YWHAZ }\end{array}$ \\
\hline Cell migration or movement & ARHGDIA, ARHGDIB, PFN1, PPIA \\
\hline Cell motility & ACTB \\
\hline \multicolumn{2}{|l|}{ Cell proliferation } \\
\hline Positive regulation & CALR \\
\hline Cytoskeleton organization & ARHGDIB, PFN1 \\
\hline Developmental process & ARHGDIB, MYL6 \\
\hline System development & PRDX1 \\
\hline Cell differentiation & CALR, RAP1A, TAGLN2 \\
\hline Epidermis development & KRT9 \\
\hline Metabolic process & ALB, BLVRB, CA1, GAPDH, HBA1/2, HBB, P4HB, PARK7, PSMB5, RAP1A \\
\hline Protein metabolic process & ACTB, CALR, P4HB, RAP1A \\
\hline Protein modification process & ACTB, CALR, HBA1/2, HBB, HIST1H3A, HSP90B1, PARK7, PFN1, PPIA, PSMB5, YWHAB \\
\hline Monosaccharide metabolic process & GAPDH, TPI1 \\
\hline Oxidation-reduction process & $\mathrm{HBA} 1 / 2, \mathrm{HBB}$ \\
\hline Response to stimulus & HBA1/2, PARK7, RAP1A \\
\hline Defense response & COTL1, HIST1H2BG, HIST1H3A \\
\hline Immune response & ACTB, ARHGDIB, HIST1H2BG, HSP90B1, PSMB5, YWHAB \\
\hline Response to stress & HSP90B1, P4HB \\
\hline Response to oxidative stress & $\mathrm{HBA} 1 / 2, \mathrm{HBB}, \mathrm{PARK} 7, \mathrm{PRDX} 1, \mathrm{PRDX} 2, \mathrm{PRDX} 6$ \\
\hline \multicolumn{2}{|l|}{ Replication } \\
\hline DNA replication & CALR, HIST1H3A, PPIA \\
\hline Senescence & CALR \\
\hline Transcription & CALR, HIST1H3A, PARK7, PRDX1, PRDX2, PSMB5, YWHAB, YWHAZ \\
\hline Translation & CALR, GAPDH \\
\hline Transport & ALB, CA1, HBA1/2, HBB, HBD, HSP90B1, RAB10, RAB5B, RAP1A \\
\hline
\end{tabular}

${ }^{2}$ Name of down-regulated proteins: ACTB Actin, cytoplasmic 1, ALB Serum albumin, ARHGDIA Rho GDP-dissociation inhibitor 1, ARHGDIB Rho GDP-dissociation inhibitor 2, BLVRB Flavin reductase (NADPH), CA1 Carbonic anhydrase 1, CALR Calreticulin, COTL1 Coactosin-like protein, GAPDH Glyceraldehyde-3-phosphate dehydrogenase, HBA1/2 Hemoglobin subunit alpha, HBB Hemoglobin subunit beta, HBD Hemoglobin subunit delta, HIST1H2BG Histone H2B type 1-C/E/F/G/l, HIST1H3A Histone H3.1, HSP9OB1 Heat shock protein $90 \mathrm{kDa}$ beta member 1, KRT9 Keratin, type I cytoskeletal 9, MYL6 Myosin light polypeptide 6, P4HB Protein disulfide-isomerase, PARK7 Protein deglycase DJ-1, PFN1 Profilin-1, PPIA Peptidyl-prolyl cis-trans isomerase A, PRDX1 Peroxiredoxin-1, PRDX2 Peroxiredoxin-2, PRDX6 Peroxiredoxin-6, PSMB5 Proteasome subunit beta type-5, RAB10 Ras-related protein Rab-10, RAB5B Ras-related protein Rab-5B, RAP1A Ras-related protein Rap-1A, TAGLN2 Transgelin-2, TPI1 Triosephosphate isomerase, YWHAB 14-3-3 protein beta/alpha, YWHAZ 14-3-3 protein zeta/delta

proliferator-activated receptor gamma (PPAR $\gamma$ ) by fatty acids resulting in upregulation of genes involved in angiogenesis, apoptosis suppression and invasion.

E-FABP and protein S100-A7, both over-expressed in our $\mathrm{N}+$ samples, stabilize the level of each other, and colocalize in focal adhesion-like structures in response to calcium, possibly as part of a protein complex with an important role in the metastatic process [82]. Abnormal expression of S100 proteins has already been detected in metastasis of colorectal cancers [83] and associated 


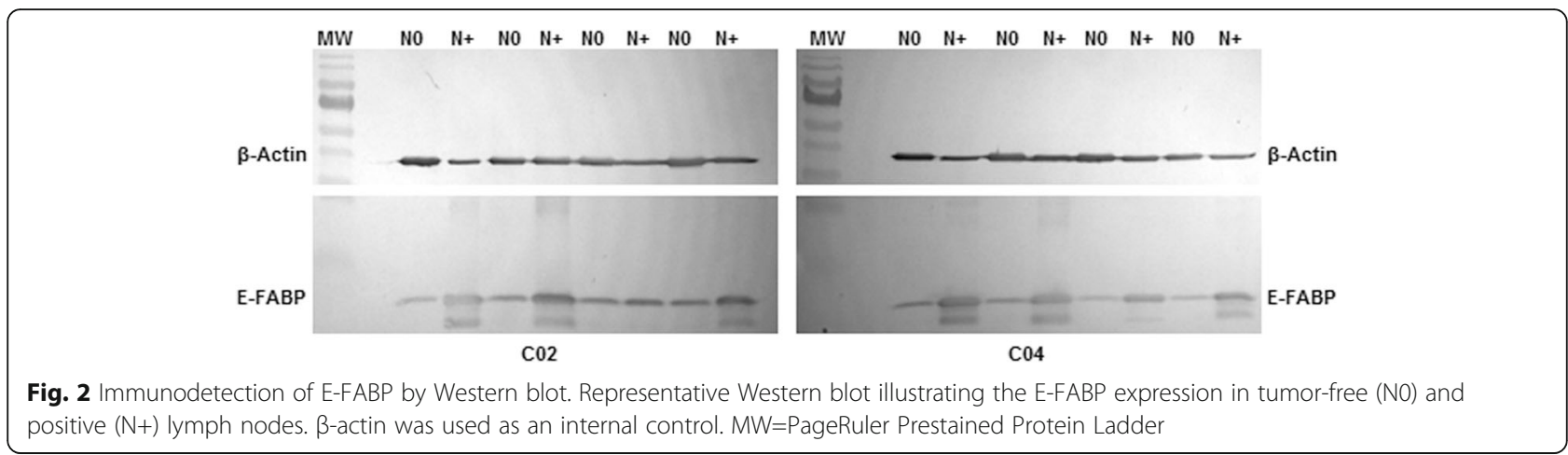

with lymph node positive tumors and invasive/migratory phenotype [84]. Similar results have been observed for apolipoprotein A-I, which also shows high expression in lymph node metastasis of primary colonic adenocarcinomas [85] and saliva and serum from HNSCC [86].

Some proteins identified by us presented opposite results to those of the literature regarding their expression in cancer cells. For example, endoplasmin and triosephosphate isomerase were found downregulated in our metastatic lymph node samples, and upregulated in tumor samples analyzed by Nomura $\mathrm{H}$ et al. [87] and Polachini GM et al. [88], which may be explained by the effect of the lymph node immune environment in modulating tumor growth or in metabolic reprogramming

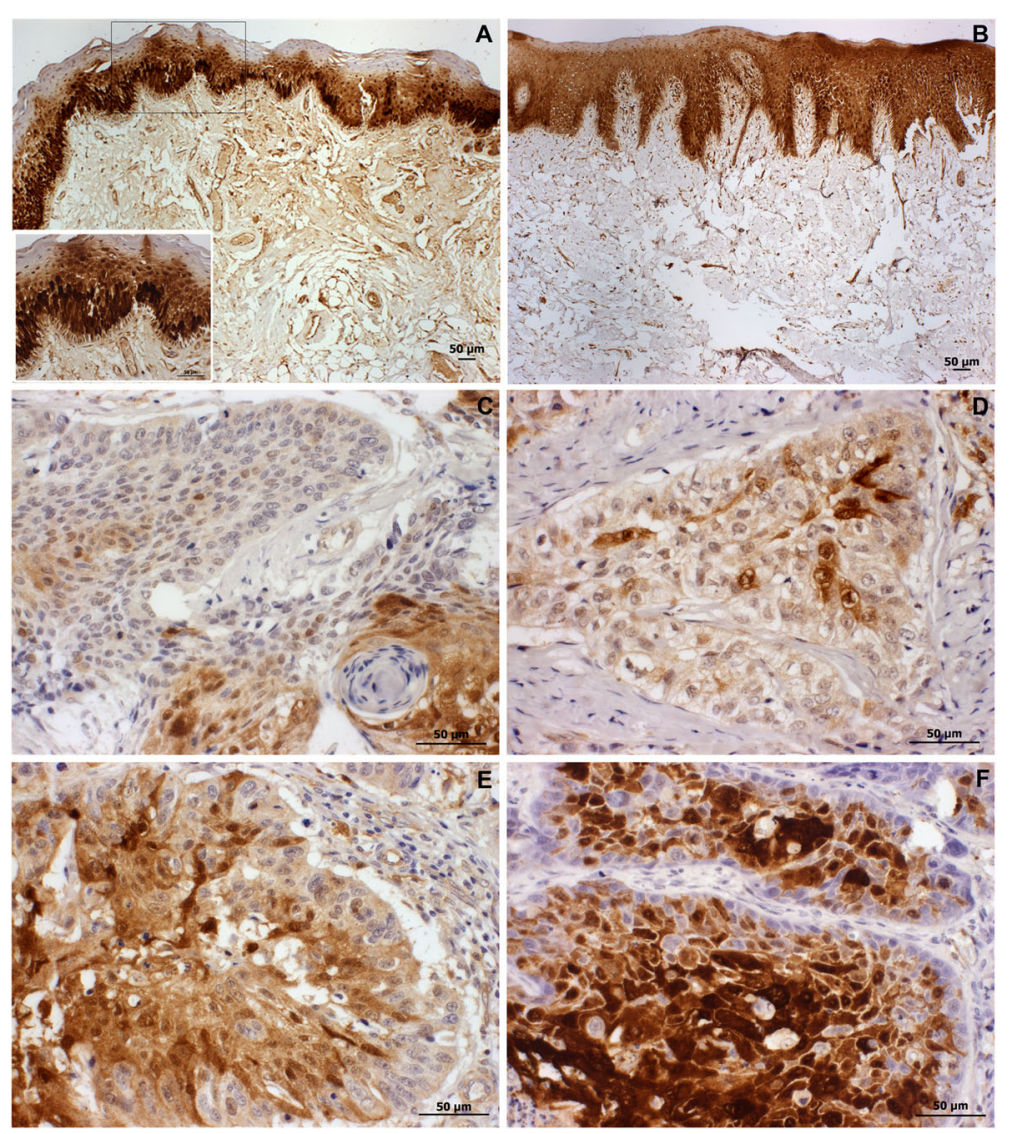

Fig. 3 Immunohistochemical analysis of E-FABP expression in oral squamous cell carcinoma and non-tumoral (margin) samples. a Intense positivity of E-FABP in nucleus and cytoplasm of the basal and spinous layer of the normal epithelium, $\mathbf{b}$ reaching all epithelial layers. Immunolabeling intensity and proportion varied in tumor samples, with (c) expression in nests of well differentiated areas, $\mathbf{d}$ heterogeneous pattern with predominance of low intensity level in tumor cells; and also (e) moderate and (f) high intensity level of staining in nests. Scale bar indicates $50 \mu \mathrm{m}$ 


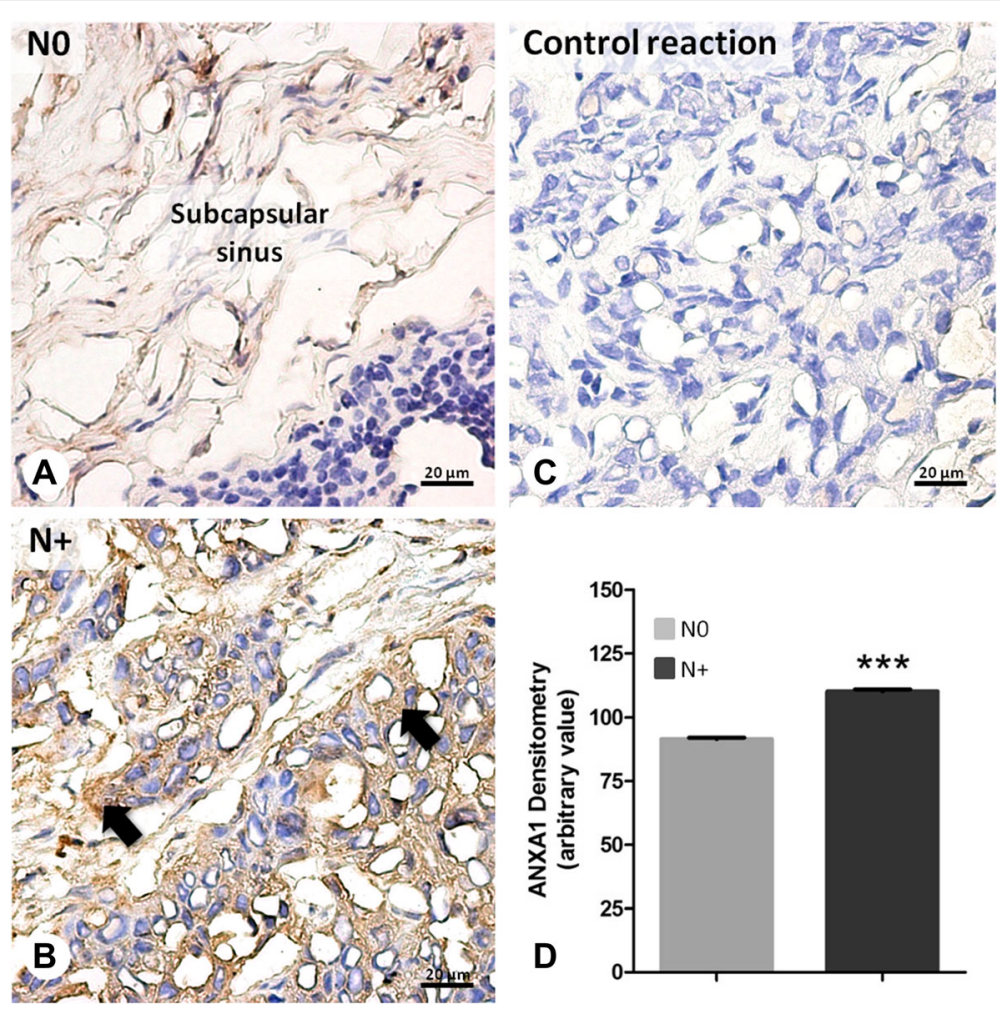

Fig. 4 Immunohistochemical analysis of ANXA1 expression in lymph nodes from head and neck carcinomas. a Non-metastatic lymph node (N0) samples: constitutive expression of ANXA1 in the subcapsular sinus. b Metastatic lymph node $(\mathrm{N}+)$ samples: endogenous ANXA1 expression increased in the lymph node tissue and in the metastatic cells (arrows). c Negative control of reaction. Sections: $2 \mu m$. Counterstain: Hematoxylin. d Densitometry of ANXA1. Values expressed as mean \pm S.E.M. ${ }^{* * *} p<0,001$

of the metastatic cell considering the blood flow, oxygen and nutrient supplies in the secondary site.

Annexin A1, a member of the annexin superfamily, has been observed underexpressed in primary HNSCC studied by us [47] and by others [48, 88]. However, our mass spectrometry and immunohistochemical analyses showed that it is overexpressed in positive lymph nodes. This is the first direct evidence of annexin A1 overexpression in lymph node metastasis of head and neck cancer. Annexin A1 is a protein involved in inflammation [89], apoptosis [90], cell differentiation [91], migration, invasion [92], and signaling [93]. It is a substrate of growth factors and kinases and exhibits abnormal (high or low) levels in several tumors and inflammatory conditions (reviewd by [94-96]. In HNSCC, ANXA1 down-regulation has been associated with poor differentiation and advanced stages [91, 97], but also with early stages, at least in laryngeal tumorigenesis [47]. In breast cancer, ANXA1 is highly expressed and modulates activation of M2 macrophage, which in its turn promotes angiogenesis, tumor progression and adaptive immune response [98]. Increased levels of annexin A1 are also observed in bronchoalveolar lavage fluid and correlated with lymphatic invasion and malignant progression of lung cancer [99]. A similar expression pattern has been described in hypoxic conditions, when it binds to formyl peptide receptors and induces cell invasion [100]. Thus, the conflicting data between our lymph node samples and previously analyzed primary tumors may indicate a complex annexin A1-cancer relationship, with distinct actions depending on the cell type, as well discussed by $\mathrm{Tu} \mathrm{Y}$ et al. [101].

At the present time, there are few biomarkers that can predict progression of head and neck carcinomas. Although the lymph node status is still the most important predictor, occult micrometastases may not be detected by the routine histopathological examination of neck dissection specimens. Therefore, markers of a well characterized metastatic phenotype could help to identify reduced numbers of neoplastic cells in lymph nodes or even before homing to and colonizing lymph nodes - the circulating tumor cells (CTCs) - using non-invasive tests. However, the number of CTCs in HNSCC patients is low and enrichment strategies need to be performed to increase CTC concentration and, consequently, to facilitate their detection and characterization [102]. Recently, Kulasinghe and collaborators [103, 104] demonstrate that CTC clusters may actually be an important HNSCC prognostic marker. In vivo and in vitro experiments should 
validate this finding and probably will help to clarify why lymphatic vessels and regional lymph nodes are the preferential target sites of head and neck carcinoma cells.

\section{Conclusions}

The present study has some methodological limitations. First, the number of expressed proteins in complex biological samples is many orders of magnitude greater than the total number of spots visible in 2-DE gels after staining. Therefore, only a small percentage of the total sample proteome is available for comparisons. Second, the usage of pools may miss relevant differences between samples. Third, the methodology of the present study does not allow to determine whether differences between groups are cause or consequence of tumorigenesis, an issue that should be the aim of future analyses, such as the analysis of cells before lymph node colonization - the circulating tumor cells.

Despite methodological limitations, this study provides, for the first time, direct evidence of annexin A1 overexpression in lymph node metastasis of head and neck cancer and adds information that may be useful for diagnosing metastatic disease. The results on the expression of heat shock proteins and enzymes of the glycolytic pathway suggest an effect of the lymph node environment in controlling tumor growth or in metabolic reprogramming of the metastatic cell. In addition, the observation of several proteins with differential expression between lymph node metastasis from tongue, floor of the mouth and larynx carcinomas reinforces the idea that head and neck sites and subsites are dissimilar entities whose behavior may be influenced by micro-environmental factors including the lymphatic network. Taken together, the results from this study contributed to our understanding of the metastatic phenotype of HNSCC and provided novel potential targets for diagnostic in metastatic head and neck squamous cell carcinomas.

\section{Additional files}

\section{Additional file 1: Clinicopathological features of 105 HNSCC patients.} (DOC $165 \mathrm{~kb}$ )

Additional file 2: Pools organized into groups according to anatomical site and presence $(\mathrm{N}+)$ or absence (NO) of tumor cells in lymph node. (DOC $39 \mathrm{~kb}$ )

Additional file 3: Two-dimensional electrophoresis maps of human lymph node proteins from HNSCC patients. (TIF $11816 \mathrm{~kb}$ )

Additional file 4: Enriched categories for 52 genes mapped to 53 DAVID identifiers. (XLSX 51 kb)

Additional file 5: Positive scores for gene-to-HNSCC association determined by HNdb hypergeometric test. (XLS $33 \mathrm{~kb}$ )

\section{Abbreviations}

1-DE: One-Dimensional Gel Electrophoresis; 2-DE: Two-Dimensional Gel Electrophoresis; ACN: Acetonitrile; ANXA1: Annexin A1; CHAPS: 3-[(3-

Cholamidopropyl) Dimethylammonio]-1-Propanesulfonate Hydrate; DAB: 3,3'-
Diaminobenzidine; DTT: Dithiothreitol; E-FABP: Fatty Acid-Binding Protein, Epidermal; EMT: Epithelial-Mesenchymal Transition; FDR: False Discovery Rate; FFPE: Formalin-Fixed, Paraffin-Embedded Tissue; HCL: Hydrochloric Acid; HGNC: Hugo Gene Nomenclature Committee; HNSCC: Head and Neck Squamous Cell Carcinoma; KEGG: Kyoto Encyclopedia of Genes and Genomes; MALDI: Matrix Assisted Laser Desorption Ionization; MS: Mass Spectrometry; N + : Lymph Node positive for neoplastic cells.; NO: Lymph Node negative for neoplastic cells; PBS: Phosphate-Buffered Saline; PPARY: Peroxisome Proliferator-Activated Receptor Gamma;

PVDF: Polyvinylidene Difluoride; Q-TOF: Quadrupole Ion Trap - Time Of Flight; SDS: Sodium Dodecyl Sulfate; TFA: Trifluoroacetic Acid; TMA: Tissue Microarray; TNM: Tumor-Node-Metastases

\section{Acknowledgments}

We are grateful to Professors Fabio C. Gozzo (University of Campinas/UNICAMP, Brasil) and Adriana F. P. Leme (Brazilian Biosciences National Laboratory/LNBio, CNPEM, Campinas) for their assistance in mass spectrometry analysis. We also thank Edilson Solim for technical support and GENCAPO (Head and Neck Genome Project -http://www.gencapo.famerp.br/) team for the valuable discussions that motivated the present study. Finally, we thank the Mass Spectrometry Laboratory at LNBio for support with the use of mass spectrometers.

\section{Funding}

This research was supported by grants from Fundação de Amparo à Pesquisa do Estado de São Paulo/FAPESP (grant number 2004/12054-9), Rede Proteoma do Estado de São Paulo/FAPESP (grant number 2004/14846-0), and Conselho Nacional de Pesquisas/CNPq (grant number 308904/2014-1).

Availability of data and materials

All data generated or analyzed during this study are included in this published article (and its Additional files).

\section{Authors' contributions}

AV participated in the design of the study, performed the 1-DE, 2-DE, MS and Western blot experiments, validated the results of 1-DE using the Scaffold software, and contributed to the manuscript preparation. GMP analyzed the 2-DE gel images using the ImageMaster 2D Platinum software, carried out the analysis and interpretation of the data, and preparation of the manuscript. MPS and SMO performed immunohistochemical analysis of ANXA1 expression in lymph node specimens and contributed to data analysis and interpretation. TH identified the metabolic pathways, associated ontologies and expression data related to the differentially expressed proteins and contributed to the interpretation of data. RVML implemented the data bank, supervised clinical data bank collection and performed data cleaning. PMC evaluated the histology and percentage of normal and tumor cells in all lymph nodes analyzed. FDN performed immunohistochemical analysis of E-FABP expression and contributed to data analysis and interpretation. JFGF and MBC recruited participants, performed sample collection and clinical evaluation of the patients. AML performed the Western blot experiments and contributed to data analysis and interpretation. EHT conceived and coordinated the design of the study, evaluated the results, contributed to drafting the manuscript and supervised all the process. All authors critically revised the manuscript, checked the accuracy of the data, and approved the version to be published.

Ethics approval and consent to participate

The study was conducted under approval of the National Committee on Ethics in Research/CONEP (reference number 1763/05, 18/05/2005) and all patients signed informed consent to participate.

\section{Consent for publication}

All patients gave written informed consent to publication of their case details, including clinical and pathology report data.

\section{Competing interests}

The authors declare that they have no competing interests.

\section{Publisher's Note}

Springer Nature remains neutral with regard to jurisdictional claims in published maps and institutional affiliations. 


\section{Author details}

'Departamento de Biologia Molecular, Faculdade de Medicina (FAMERP), Av. Brigadeiro Faria Lima, 5416, Vila São Pedro, São José do Rio Preto, SP CEP 15090-000, Brazil. ${ }^{2}$ Departamento de Biologia, Instituto de Biociências, Letras e Ciências Exatas (IBILCE), Universidade Estadual Paulista (UNESP), R. Cristóvão Colombo, 2265, São José do Rio Preto, SP CEP 15054-000, Brazil. ${ }^{3}$ Instituto do Câncer de São Paulo Octavio Frias de Oliveira - ICESP, Av. Dr. Arnaldo, 251 Cerqueira César, São Paulo, SP CEP 01246-000, Brazil. ${ }^{4}$ Faculdade Ceres (Faceres), Av. Anísio Haddad, 6751, São José do Rio Preto, SP CEP 15090-305, Brazil. ${ }^{5}$ Departamento de Estomatologia, Faculdade de Odontologia, Universidade de São Paulo, Av. Prof. Lineu Prestes, 2227, São Paulo, SP CEP 05508-000, Brazil. ${ }^{6}$ Instituto do Câncer Arnaldo Vieira de Carvalho, R. Dr Cesário Mota Jr, 112, São Paulo, SP CEP 01221-020, Brazil. 'Departamento de Cirurgia de Cabeça e Pescoço, Hospital Heliópolis, R. Cônego Xavier, 276, São Paulo, SP CEP 04231-030, Brazil. ${ }^{8}$ Departamento de Análises Clínicas, Toxicológicas e Bromatológicas, Faculdade de Ciências Farmacêuticas, Universidade de São Paulo, Avenida do Café, s/n, Ribeirão Preto, SP CEP 14040-903, Brazil. 'Departamento de Genética e Biologia Evolutiva, Instituto de Biociências, Universidade de São Paulo, R. do Matão, 321, São Paulo, SP CEP 05508-090, Brazil.

\section{Received: 2 October 2017 Accepted: 2 August 2018}

\section{Published online: 29 August 2018}

\section{References}

1. Sporn MB. The war on cancer. Lancet. 1996:347(9012):1377-81.

2. Nguyen DX, Massague J. Genetic determinants of cancer metastasis. Nat Rev Genet. 2007:8(5):341-52.

3. Yang J, Weinberg RA. Epithelial-mesenchymal transition: at the crossroads of development and tumor metastasis. Dev Cell. 2008;14(6):818-29.

4. Polyak K, Weinberg RA. Transitions between epithelial and mesenchymal states: acquisition of malignant and stem cell traits. Nat Rev Cancer. 2009; 9(4):265-73.

5. Harris AL. Hypoxia--a key regulatory factor in tumour growth. Nat Rev Cancer. 2002;2(1):38-47.

6. Brooks SA, Lomax-Browne HJ, Carter TM, Kinch CE, Hall DM. Molecular interactions in cancer cell metastasis. Acta Histochem. 2009;112:3-25.

7. Blood $\mathrm{CH}$, Zetter BR. Tumor interactions with the vasculature: angiogenesis and tumor metastasis. Biochim Biophys Acta. 1990;1032(1):89-118.

8. Ji RC. Lymph node lymphangiogenesis: a new concept for modulating tumor metastasis and inflammatory process. Histol Histopathol. 2009:24(3):377-84

9. Zlotnik A. Chemokines in neoplastic progression. Semin Cancer Biol. 2004; 14(3):181-5.

10. Saharinen P, Tammela T, Karkkainen MJ, Alitalo K. Lymphatic vasculature: development, molecular regulation and role in tumor metastasis and inflammation. Trends Immunol. 2004;25(7):387-95.

11. Paduch $R$. The role of lymphangiogenesis and angiogenesis in tumor metastasis. Cell Oncol (Dordr). 2016:39(5):397-410.

12. Timar J, Csuka O, Remenar E, Repassy G, Kasler M. Progression of head and neck squamous cell cancer. Cancer Metastasis Rev. 2005;24(1):107-27.

13. Swartz MA, Lund AW. Lymphatic and interstitial flow in the tumour microenvironment: linking mechanobiology with immunity. Nat Rev Cancer 2012;12(3):210-9.

14. Maula SM, Luukkaa M, Grenman R, Jackson D, Jalkanen S, Ristamaki R. Intratumoral lymphatics are essential for the metastatic spread and prognosis in squamous cell carcinomas of the head and neck region. Cancer Res. 2003;63(8):1920-6.

15. Kaplan RN, Riba RD, Zacharoulis S, Bramley AH, Vincent L, Costa C, MacDonald DD, Jin DK, Shido K, Kerns SA, et al. VEGFR1-positive haematopoietic bone marrow progenitors initiate the pre-metastatic niche. Nature. 2005;438(7069):820-7.

16. Deng J, Liu Y, Lee H, Herrmann A, Zhang W, Zhang C, Shen S, Priceman SJ, Kujawski M, Pal SK, et al. S1PR1-STAT3 signaling is crucial for myeloid cell colonization at future metastatic sites. Cancer Cell. 2012;21(5):642-54.

17. Joyce JA, Pollard JW. Microenvironmental regulation of metastasis. Nat Rev Cancer. 2009:9(4):239-52.

18. Lorusso G, Ruegg C. New insights into the mechanisms of organ-specific breast cancer metastasis. Semin Cancer Biol. 2012;22(3):226-33.

19. Langley RR, Fidler IJ. The seed and soil hypothesis revisited--the role of tumor-stroma interactions in metastasis to different organs. Int J Cancer. 2011;128(11):2527-35.
20. Mathot $L$, Stenninger J. Behavior of seeds and soil in the mechanism of metastasis: a deeper understanding. Cancer Sci. 2012;103(4):626-31.

21. Genden EM, Ferlito A, Bradley PJ, Rinaldo A, Scully C. Neck disease and distant metastases. Oral Oncol. 2003:39(3):207-12.

22. Renner G. Small cell carcinoma of the head and neck: a review. Semin Oncol. 2007:34(1):3-14

23. Witt RL. Major salivary gland cancer. Surg Oncol Clin N Am. 2004;13(1):113-27.

24. Okura M, Aikawa T, Sawai NY, lida S, Kogo M. Decision analysis and treatment threshold in a management for the NO neck of the oral cavity carcinoma. Oral Oncol. 2009;45(10):908-11.

25. Sobin LH, Wittekind C: TNM classification of malignant Tumours; 2002.

26. de Marqui AB, Vidotto A, Polachini GM, Bellato Cde M, Cabral H, Leopoldino AM, de Gois Filho JF, Fukuyama EE, Settanni FA, Cury PM, et al. Solubilization of proteins from human lymph node tissue and two-dimensional gel storage. J Biochem Mol Biol. 2006:39(2):216-22.

27. Bradford MM. A rapid and sensitive method for the quantitation of microgram quantities of protein utilizing the principle of protein-dye binding. Anal Biochem. 1976;72:248-54

28. Laemmli UK. Cleavage of structural proteins during the assembly of the head of bacteriophage T4. Nature. 1970;227(5259):680-5.

29. Paes Leme AF, Sherman NE, Smalley DM, Sizukusa LO, Oliveira AK, Menezes MC, Fox JW, Serrano SM. Hemorrhagic activity of HF3, a snake venom metalloproteinase: insights from the proteomic analysis of mouse skin and blood plasma. J Proteome Res. 2012;11(1):279-91.

30. Henrique $T$, Jose Freitas da Silveira N, Henrique Cunha Volpato A, Mioto MM, Carolina Buzzo Stefanini A, Bachir Fares A, da Silva Castro G, Andrade J, Masson C, Veronica Mendoza Lopez R, Daumas Nunes F, et al. HNdb: an integrated database of gene and protein information on head and neck squamous cell carcinoma. Database. 2016;2016. https://doi.org/10.1093/ database/baw026.

31. Kanehisa M, Goto S. KEGG: Kyoto encyclopedia of genes and genomes. Nucleic Acids Res. 2000;28(1):27-30.

32. Ashburner M, Ball CA, Blake JA, Botstein D, Butler H, Cherry JM, Davis AP, Dolinski K, Dwight SS, Eppig JT, et al. Gene ontology: tool for the unification of biology. The gene ontology consortium. Nat Genet. 2000;25(1):25-9.

33. Edgar R, Domrachev M, Lash AE. Gene expression omnibus: NCBI gene expression and hybridization array data repository. Nucleic Acids Res. 2002; 30(1):207-10.

34. da Huang W, Sherman BT, Lempicki RA. Bioinformatics enrichment tools: paths toward the comprehensive functional analysis of large gene lists. Nucleic Acids Res. 2009;37(1):1-13.

35. da Huang W, Sherman BT, Lempicki RA. Systematic and integrative analysis of large gene lists using DAVID bioinformatics resources. Nat Protoc. 2009; 4(1):44-57.

36. Dvorakova M, Jerabkova J, Prochazkova I, Lenco J, Nenutil R, Bouchal P. Transgelin is upregulated in stromal cells of lymph node positive breast cancer. J Proteome. 2016:132:103-11.

37. Flores-Perez A, Marchat LA, Sanchez LL, Romero-Zamora D, Arechaga-Ocampo E, Ramirez-Torres N, Chavez JD, Carlos-Reyes A, Astudillo-de la Vega H, Ruiz-Garcia E, et al. Differential proteomic analysis reveals that EGCG inhibits HDGF and activates apoptosis to increase the sensitivity of non-small cells lung cancer to chemotherapy. Proteomics Clin Appl. 2016;10(2):172-82.

38. Haonon $\mathrm{O}$, Rucksaken R, Pinlaor P, Pairojkul C, Chamgramol Y, Intuyod K, Onsurathum S, Khuntikeo N, Pinlaor S. Upregulation of 14-3-3 eta in chronic liver fluke infection is a potential diagnostic marker of cholangiocarcinoma. Proteomics Clin Appl. 2016;10(3):248-56.

39. Peng XC, Gong FM, Chen Y, Qiu M, Cheng K, Tang J, Ge J, Chen N, Zeng H, Liu JY. Proteomics identification of PGAM1 as a potential therapeutic target for urothelial bladder cancer. J Proteome. 2016;132:85-92.

40. Camisasca DR, da Ros GL, Soares MR, Sandim V, Nogueira FC, Garcia CH, Santana R, de Oliveira SP, Buexm LA, de Faria PA, et al. A proteomic approach to compare saliva from individuals with and without oral leukoplakia. J Proteome. 2017;151:43-52.

41. Oliveira BM, Coorssen JR, Martins-de-Souza D. 2DE: the phoenix of proteomics. J Proteome. 2014;104:140-50.

42. Fukumoto S, Yamauchi N, Moriguchi H, Hippo Y, Watanabe A, Shibahara J, Taniguchi H, Ishikawa S, Ito H, Yamamoto S, et al. Overexpression of the aldo-keto reductase family protein AKR1B10 is highly correlated with smokers' non-small cell lung carcinomas. Clin Cancer Res. 2005;11(5):1776-85.

43. Penning TM. AKR1B10: a new diagnostic marker of non-small cell lung carcinoma in smokers. Clin Cancer Res. 2005;11(5):1687-90. 
44. Chen J, He QY, Yuen AP, Chiu JF. Proteomics of buccal squamous cell carcinoma: the involvement of multiple pathways in tumorigenesis. Proteomics. 2004;4(8):2465-75.

45. Wang Z, Feng X, Liu X, Jiang L, Zeng X, Ji N, Li J, Li L, Chen Q. Involvement of potential pathways in malignant transformation from oral leukoplakia to oral squamous cell carcinoma revealed by proteomic analysis. BMC Genomics. 2009;10:383

46. He QY, Chen J, Kung HF, Yuen AP, Chiu JF. Identification of tumorassociated proteins in oral tongue squamous cell carcinoma by proteomics. Proteomics. 2004:4(1):271-8.

47. Alves VA, Nonogaki S, Cury PM, Wunsch-Filho V, de Carvalho MB, Michaluart-Junior P, Moyses RA, Curioni OA, Figueiredo DL, ScapulatempoNeto $C$, et al. Annexin A1 subcellular expression in laryngeal squamous cell carcinoma. Histopathology. 2008;53(6):715-27.

48. Silistino-Souza R, Rodrigues-Lisoni FC, Cury PM, Maniglia JV, Raposo LS, Tajara EH, Christian HC, Oliani SM. Annexin 1: differential expression in tumor and mast cells in human larynx cancer. Int J Cancer. 2007;120(12):2582-9.

49. Uma RS, Naresh KN, D'Cruz AK, Mulherkar R, Borges AM. Metastasis of squamous cell carcinoma of the oral tongue is associated with downregulation of epidermal fatty acid binding protein (E-FABP). Oral Oncol. 2007:43(1):27-32.

50. Fang LY, Wong TY, Chiang WF, Chen YL. Fatty-acid-binding protein 5 promotes cell proliferation and invasion in oral squamous cell carcinoma. J Oral Pathol Med. 2010;39(4):342-8.

51. Zhu Z, Xu X, Yu Y, Graham M, Prince ME, Carey TE, Sun D. Silencing heat shock protein 27 decreases metastatic behavior of human head and neck squamous cell cancer cells in vitro. Mol Pharm. 2010;7(4):1283-90.

52. Lee JH, Sun D, Cho KJ, Kim MS, Hong MH, Kim IK, Lee JS. Overexpression of human $27 \mathrm{kDa}$ heat shock protein in laryngeal cancer cells confers chemoresistance associated with cell growth delay. J Cancer Res Clin Oncol. 2007;133(1):37-46.

53. Saussez S, Decaestecker C, Lorfevre F, Cucu DR, Mortuaire G, Chevalier D, Wacreniez A, Kaltner H, Andre S, Toubeau G, et al. High level of galectin-1 expression is a negative prognostic predictor of recurrence in laryngeal squamous cell carcinomas. Int J Oncol. 2007;30(5):1109-17.

54. Alves PM, Godoy GP, Gomes DQ, Medeiros AM, de Souza LB, da Silveira EJ, Vasconcelos MG, Queiroz LM. Significance of galectins-1, $-3,-4$ and -7 in the progression of squamous cell carcinoma of the tongue. Pathol Res Pract. 2011;207(4):236-40.

55. Masood N, Malik FA, Kayani MA. Expression of xenobiotic metabolizing genes in head and neck cancer tissues. Asian Pac J Cancer Prev : APJCP. 2011;12(2):377-82.

56. Masood N, Kayani MA. Expression patterns of carcinogen detoxifying genes (CYP1A1, GSTP1 \& GSTT1) in HNC patients. Pathol Oncol Res : POR. 2013; 19(1):89-94.

57. Yamashina M, Sato K, Tonogi M, Tanaka Y, Yamane GY, Katakura A. Evaluation of superficial oral squamous cell malignancy based on morphometry and immunoexpression of cytokeratin 13 and cytokeratin 17. Acta Cytol. 2014;58(1):67-75.

58. Hamakawa H, Fukuzumi M, Bao Y, Sumida T, Kayahara H, Onishi A, Sogawa K. Keratin mRNA for detecting micrometastasis in cervical lymph nodes of oral cancer. Cancer Lett. 2000;160(1):115-23.

59. Takahashi M, Suzuki S, Ishikawa K. Cyclophilin A-EMMPRIN interaction induces invasion of head and neck squamous cell carcinoma. Oncol Rep. 2012;27(1):198-203.

60. Huang CF, Sun ZJ, Zhao YF, Chen XM, Jia J, Zhang WF. Increased expression of peroxiredoxin 6 and cyclophilin a in squamous cell carcinoma of the tongue. Oral Dis. 2011;17(3):328-34.

61. Kudo Y, lizuka S, Yoshida M, Nguyen PT, Siriwardena SB, Tsunematsu T, Ohbayashi M, Ando T, Hatakeyama D, Shibata T, et al. Periostin directly and indirectly promotes tumor lymphangiogenesis of head and neck cancer. PLoS One. 2012;7(8):e44488.

62. Shen Z, Jiang Z, Ye D, Xiao B, Zhang X, Guo J. Growth inhibitory effects of DJ-1-small interfering RNA on laryngeal carcinoma Hep-2 cells. Med Oncol. 2011;28(2):601-7.

63. Zhu XL, Wang ZF, Lei WB, Zhuang HW, Hou WJ, Wen YH, Wen WP. Tumorigenesis role and clinical significance of DJ-1, a negative regulator of PTEN, in supraglottic squamous cell carcinoma. J Exp Clin Cancer Res : CR. 2012;31:94.

64. Tripathi SC, Matta A, Kaur J, Grigull J, Chauhan SS, Thakar A, Shukla NK, Duggal R, DattaGupta S, Ralhan R, et al. Nuclear S100A7 is associated with poor prognosis in head and neck cancer. PLoS One. 2010;5(8):e11939.
65. Kesting MR, Sudhoff H, Hasler RJ, Nieberler M, Pautke C, Wolff KD, Wagenpfeil S, Al-Benna S, Jacobsen F, Steinstraesser L. Psoriasin (S100A7) up-regulation in oral squamous cell carcinoma and its relation to clinicopathologic features. Oral Oncol. 2009;45(8):731-6.

66. Mitra RS, Zhang Z, Henson BS, Kurnit DM, Carey TE, D'Silva NJ. Rap1A and rap1B ras-family proteins are prominently expressed in the nucleus of squamous carcinomas: nuclear translocation of GTP-bound active form. Oncogene. 2003;22(40):6243-56.

67. Thul PJ, Lindskog C. The human protein atlas: a spatial map of the human proteome. Protein Sci. 2018;27(1):233-44.

68. Severino P, Alvares AM, Michaluart P Jr, Okamoto OK, Nunes FD, MoreiraFilho CA, Tajara EH. Global gene expression profiling of oral cavity cancers suggests molecular heterogeneity within anatomic subsites. BMC Res Notes. 2008;1:113.

69. Krop I, Marz A, Carlsson H, Li X, Bloushtain-Qimron N, Hu M, Gelman R, Sabel MS, Schnitt S, Ramaswamy S, et al. A putative role for psoriasin in breast tumor progression. Cancer Res. 2005;65(24):11326-34.

70. Le QT, Shi G, Cao H, Nelson DW, Wang Y, Chen EY, Zhao S, Kong C, Richardson D, O'Byrne KJ, et al. Galectin-1: a link between tumor hypoxia and tumor immune privilege. J Clin Oncol. 2005;23(35):8932-41.

71. Biron-Shental T, Schaiff WT, Ratajczak CK, Bildirici I, Nelson DM, Sadovsky Y. Hypoxia regulates the expression of fatty acid-binding proteins in primary term human trophoblasts. Am J Obstet Gynecol. 2007;197(5):516 e511-6.

72. Chaudary N, Hill RP. Increased expression of metastasis-related genes in hypoxic cells sorted from cervical and lymph nodal xenograft tumors. Lab Invest. 2009;89(5):587-96.

73. Chaudary N, Hill RP. Hypoxia and metastasis. Clin Cancer Res. 2007;13(7): 1947-9.

74. Gry M, Rimini R, Stromberg S, Asplund A, Ponten F, Uhlen M, Nilsson P. Correlations between RNA and protein expression profiles in 23 human cell lines. BMC Genomics. 2009;10:365.

75. Rauch J, Ahlemann M, Schaffrik M, Mack B, Ertongur S, Andratschke M, Zeidler R, Lang S, Gires O. Allogenic antibody-mediated identification of head and neck cancer antigens. Biochem Biophys Res Commun. 2004; 323(1):156-62

76. Melle C, Ernst G, Winkler R, Schimmel B, Klussmann JP, Wittekindt C, Guntinas-Lichius O, von Eggeling F. Proteomic analysis of human papillomavirus-related oral squamous cell carcinoma: identification of thioredoxin and epidermal-fatty acid binding protein as upregulated protein markers in microdissected tumor tissue. Proteomics. 2009;9(8):2193-201.

77. Lopez RV, Levi JE, Eluf-Neto J, Koifman RJ, Koifman S, Curado MP, Michaluart-Junior P, Figueiredo DL, Saggioro FP, de Carvalho MB, et al. Human papillomavirus (HPV) 16 and the prognosis of head and neck cancer in a geographical region with a low prevalence of HPV infection. Cancer Causes Control : CCC. 2014;25(4):461-71.

78. Pang J, Liu WP, Liu XP, Li LY, Fang YQ, Sun QP, Liu SJ, Li MT, Su ZL, Gao X Profiling protein markers associated with lymph node metastasis in prostate cancer by DIGE-based proteomics analysis. J Proteome Res. 2010;9(1):216-26.

79. Fujita K, Kume H, Matsuzaki K, Kawashima A, Ujike T, Nagahara A, Uemura M, Miyagawa Y, Tomonaga T, Nonomura N. Proteomic analysis of urinary extracellular vesicles from high Gleason score prostate cancer. Sci Rep. 2017;7:42961.

80. Wang W, Chu HJ, Liang YC, Huang JM, Shang CL, Tan H, Liu D, Zhao YH, Liu TY, Yao SZ. FABP5 correlates with poor prognosis and promotes tumor cell growth and metastasis in cervical cancer. Tumour Biol. 2016;37(11):14873-83.

81. Bao Z, Malki MI, Forootan SS, Adamson J, Forootan FS, Chen D, Foster CS, Rudland PS, Ke Y. A novel cutaneous fatty acid-binding protein-related signaling pathway leading to malignant progression in prostate cancer cells. Genes Cancer. 2013;4(7-8):297-314.

82. Ruse M, Broome AM, Eckert RL. S100A7 (psoriasin) interacts with epidermal fatty acid binding protein and localizes in focal adhesion-like structures in cultured keratinocytes. J Invest Dermatol. 2003;121(1):132-41.

83. Melle C, Ernst G, Schimmel B, Bleul A, von Eggeling F. Colon-derived liver metastasis, colorectal carcinoma, and hepatocellular carcinoma can be discriminated by the ca(2+)-binding proteins S100A6 and S100A11. PLoS One. 2008;3(12):e3767.

84. Al-Haddad S, Zhang Z, Leygue E, Snell L, Huang A, Niu Y, Hiller-Hitchcock T, Hole K, Murphy LC, Watson PH. Psoriasin (S100A7) expression and invasive breast cancer. Am J Pathol. 1999;155(6):2057-66.

85. Tachibana M, Ohkura Y, Kobayashi Y, Sakamoto H, Tanaka Y, Watanabe J, Amikura K, Nishimura Y, Akagi K. Expression of apolipoprotein A1 in colonic adenocarcinoma. Anticancer Res. 2003;23(5b):4161-7. 
86. Vidotto A, Henrique T, Raposo LS, Maniglia JV, Tajara EH. Salivary and serum proteomics in head and neck carcinomas: before and after surgery and radiotherapy. Cancer Biomark. 2010;8(2):95-107.

87. Nomura H, Uzawa K, Yamano Y, Fushimi K, Ishigami T, Kato Y, Saito K, Nakashima D, Higo M, Kouzu Y, et al. Network-based analysis of calciumbinding protein genes identifies Grp94 as a target in human oral carcinogenesis. Br J Cancer. 2007;97(6):792-801.

88. Polachini GM, Sobral LM, Mercante AM, Paes-Leme AF, Xavier FC, Henrique T, Guimaraes DM, Vidotto A, Fukuyama EE, Gois-Filho JF, et al. Proteomic approaches identify members of cofilin pathway involved in oral tumorigenesis. PLoS One. 2012;7(12):e50517.

89. de Jong R, Leoni $\mathrm{G}$, Drechsler M, Soehnlein $\mathrm{O}$. The advantageous role of annexin A1 in cardiovascular disease. Cell Adhes Migr. 2017;11(3):261-74.

90. Zhang X, Li X, Zheng L, Lei L. ANXA1 silencing increases the sensitivity of cancer cells to low-concentration arsenic trioxide treatment by inhibiting ERK MAPK activation. Tumori. 2015;101(4):360-7.

91. Zhu DW, Yang X, Yang CZ, Ma J, Liu Y, Yan M, Wang LZ, Li J, Zhang CP, Zhang ZY, et al. Annexin A1 down-regulation in oral squamous cell carcinoma correlates to pathological differentiation grade. Oral Oncol. 2013; 49(6):542-50.

92. Han G, Lu K, Huang J, Ye J, Dai S, Ye Y, Zhang L. Effect of Annexin A1 gene on the proliferation and invasion of esophageal squamous cell carcinoma cells and its regulatory mechanisms. Int J Mol Med. 2017;39(2):357-63.

93. Pantaleao L, Rocha GHO, Reutelingsperger C, Tiago M, Maria-Engler SS, Solito E, Farsky SP. Connections of annexin A1 and translocator protein-18kDa on toll like receptor stimulated BV-2 cells. Exp Cell Res. 2018;367:282-90.

94. Guo C, Liu S, Sun MZ. Potential role of Anxa1 in cancer. Future Oncol. 2013; 9(11):1773-93.

95. Galvao I, Vago JP, Barroso LC, Tavares LP, Queiroz-Junior CM, Costa W, Carneiro FS, Ferreira TP, Silva PM, Amaral FA, et al. Annexin A1 promotes timely resolution of inflammation in murine gout. Eur J Immunol. 2017; 47(3):585-96.

96. Hassan MN, Belibasakis GN, Gumus P, Ozturk VO, Emingil G, Bostanci N. Annexin-1 as a salivary biomarker for gingivitis during pregnancy. J Periodontol. 2018; https://doi.org/10.1002/JPER.17-0557.

97. Wan YM, Tian J, Qi L, Liu LM, Xu N. ANXA1 affects cell proliferation, invasion and epithelial-mesenchymal transition of oral squamous cell carcinoma. Exp Ther Med. 2017;14(5):5214-8.

98. Moraes LA, Kar S, Foo SL, Gu T, Toh YQ, Ampomah PB, Sachaphibulkij K, Yap $\mathrm{G}$, Zharkova O, Lukman HM, et al. Annexin-A1 enhances breast cancer growth and migration by promoting alternative macrophage polarization in the tumour microenvironment. Sci Rep. 2017;7(1):17925.

99. Biaoxue R, Xiguang C, Hua L, Tian F, Wenlong G. Increased level of annexin A1 in bronchoalveolar lavage fluid as a potential diagnostic indicator for lung cancer. Int J Biol Markers. 2017;32(1):e132-40.

100. Bizzarro V, Belvedere R, Migliaro V, Romano E, Parente L, Petrella A. Hypoxia regulates ANXA1 expression to support prostate cancer cell invasion and aggressiveness. Cell Adhes Migr. 2016:1-14. https://doi.org/10.1080/ 19336918.2016 .1259056$.

101. Tu Y, Johnstone CN, Stewart AG. Annexin A1 influences in breast cancer: controversies on contributions to tumour, host and immunoediting processes. Pharmacol Res. 2017;119:278-88.

102. Kulasinghe A, Kenny L, Perry C, Thiery JP, Jovanovic L, Vela I, Nelson C, Punyadeera C. Impact of label-free technologies in head and neck cancer circulating tumour cells. Oncotarget. 2016;7(44):71223-34.

103. Kulasinghe A, Tran TH, Blick T, O'Byrne K, Thompson EW, Warkiani ME, Nelson C, Kenny L, Punyadeera C. Enrichment of circulating head and neck tumour cells using spiral microfluidic technology. Sci Rep. 2017;7:42517.

104. Kulasinghe A, Schmidt H, Perry C, Whitfield B, Kenny L, Nelson C, Warkiani $M E$, Punyadeera C. A collective route to head and neck Cancer metastasis. Sci Rep. 2018:8(1):746.

\section{Ready to submit your research? Choose BMC and benefit from:}

- fast, convenient online submission

- thorough peer review by experienced researchers in your field

- rapid publication on acceptance

- support for research data, including large and complex data types

- gold Open Access which fosters wider collaboration and increased citations

- maximum visibility for your research: over $100 \mathrm{M}$ website views per year

At BMC, research is always in progress.

Learn more biomedcentral.com/submissions 